\title{
FRONTEIRA DE PRODUÇÃO ESTOCÁSTICA E EFICIÊNCIA TÉCNICA NA AGRICULTURA
}

JÚNIA CRISTINA PÉRES RODRIGUES DA CONCEIÇÃO

Economista

Orientador: Prof. Dr. PAULO FERNANDO CIDADE DE ARAÚJO

Tese apresentada à Escola Superior de Agricultura "Luiz de Queiroz", Universidade de São Paulo, para obtenção do título de Doutor em Ciências, Área de Concentração: Economia Aplicada. 


\section{Dados Internacionais de Catalogação na Publicação (CIP) DIVISĀO DE BIBLIOTECA E DOCUMENTAÇĀO - Campus "Luiz de Queiroz"/USP}

Conceição, Júnia Cristina Péres Rodrigues da Conceiçāo

Fronteira de produçāo estocástica e eficiência técnica na agricultura / Júnia

Cristina Péres Rodrigues da Conceição. - Piracicaba, 1998.

$108 \mathrm{p}$.

Tese (doutorado) - - Escola Superior de Agricultura Luiz de Queiroz, 1998. Bibliografia.

1. Agricultura comercial 2. Economia agricola 3. Econometria 4. Eficiência técnica 5. Funçăo de produçăo 6. Modelo matemático 7. Modernização agricola 8. Produtor rural l. Titulo

CDD 338.16 


\section{FRONTEIRA DE PRODUÇÃO ESTOCÁSTICA E EFICIÊNCIA TÉCNICA NA AGRICULTURA}

JÚNIA CRISTINA PÉRES RODRIGUES DA CONCEIÇÃO

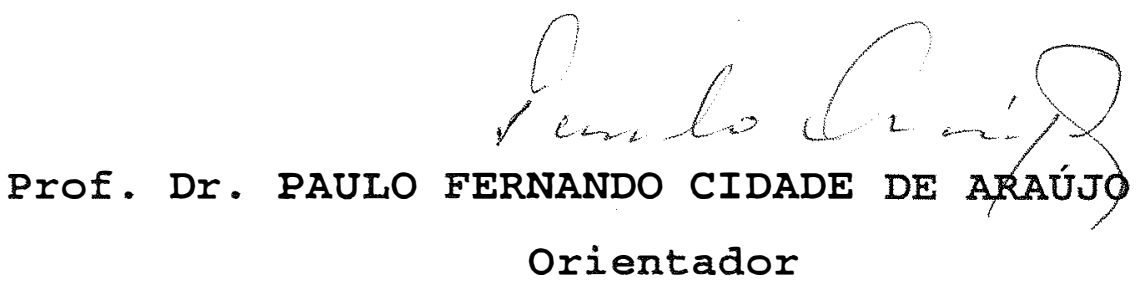




\section{Ofereço}

aos meus pais, peio exemplo.

\section{Dedico}

Ao meu marido, Pedro Henrique, meu amor, e ao pedro Vítor, meu filho e amigo, minha grande emoção. 


\section{A G R A D E C I M E N T O S}

Ao Professor Paulo Fernando Cidade de Araújo, meu orientador, que durante esses anos de convivência se transformou em um grande e especial amigo. Sua dedicação e eficiência na orientação deste trabalho foram, sem dúvida, de fundamental importância.

Às professoras Miriam Rumenos Piedade Bacchi e Ana Lúcia Kassouf pelas valiosas contribuições, meus sinceros agradecimentos. Ao professor Joaquim José Martins Guilhoto pelas observações feitas.

Ao Dr. José Garcia Gasques, ao Alexandre Carvalho e ao shyuiti pelo apoio recebido durante a execução deste trabalho. Ao Dr. Geraldo Souza Silva pelo valioso auxílio no uso do programa estatístico utilizado nesta tese.

Aos funcionários e amigos do DESR/ESALQ/USP, em especial à Lu, Cristiane, Elenice, Maielli, Márcia, Pedro e Valdeci pelo apoio e amizade. À Helena, pelo eficiente trabalho na revisão das normas para elaboração desta tese.

Aos amigos Alivínio e Dilza, Uilson e Márcia Previtalli pela fraterna convivência na ESALQ.

Aos amigos Susy, Ricardo, João Ricardo,

Maíra, Dona Mercedes pela alegre e sincera convivência durante minha estada em Piracicaba.

À Marilza e Denilson, pelo incentivo e amizade. 
Ao Departamento de Economia e Sociologia Rural da ESALQ/USP, à CAPES e ao IPEA pelo apoio recebido.

Aos meus pais, Jeremias e Dirce, pelo incentivo constante. Ao Márcio e Fernanda, Marquinhos, Ana Cláudia e Letícia pelo carinho e estímulo. Ao meu sogro, Pedro (in memorian), e à minha sogra Léa pelo incentivo.

Last but not the least, ao Pedro Henrique, meu marido, e ao pedro Vítor, meu filho, meus companheiros de todas as horas, o meu eterno agradecimento. Sem eles, tudo teria sido mais difícil. 


\section{SUTMÁRIO}

Página

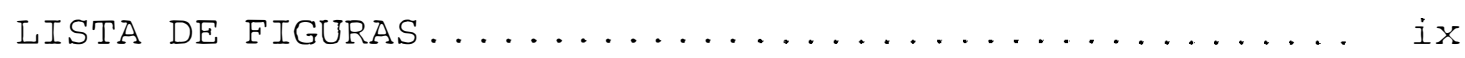

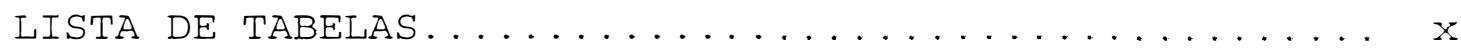

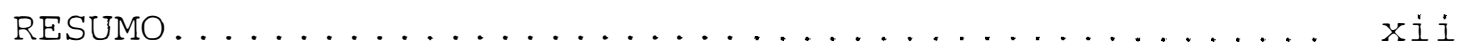

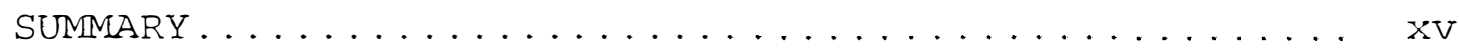

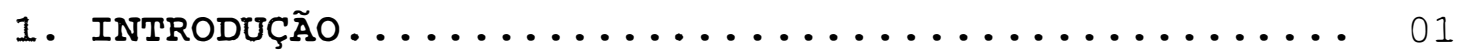

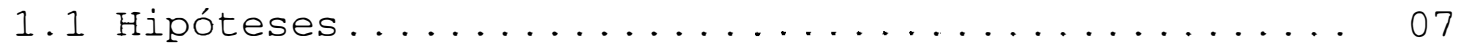

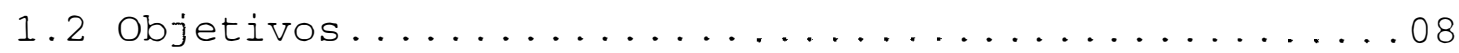

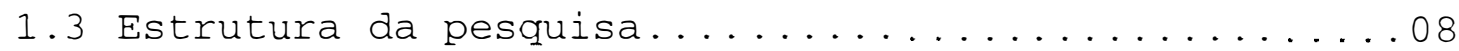

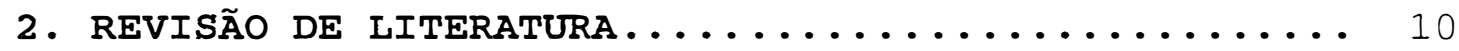

2.1. Fontes de crescimento na agricultura brasileira:

expansão da área, produtividade e eficiência....10

2.2. Fundamentação teórica sobre fronteiras de produção e medidas de eficiência técnica...... 18

2.3. Aplicações empíricas do modelo de fronteira

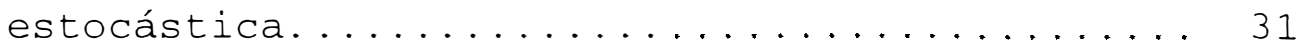

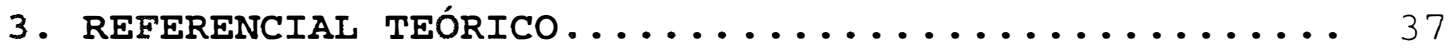

3.1. A função de produção fronteira e a medida

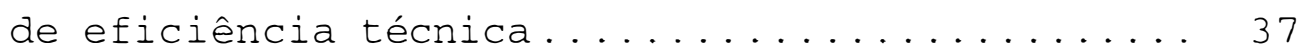

4. METODOLOGIA........................... 46

4.1. Modelo empírico da função fronteira.......... 46

4.2. Definição das variáveis da função fronteira.... 48

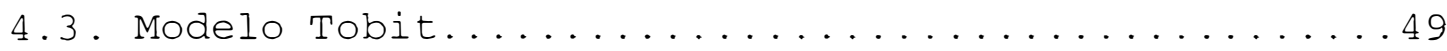

4.4. Definição das variáveis do modelo Tobit........53

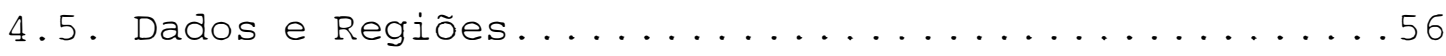




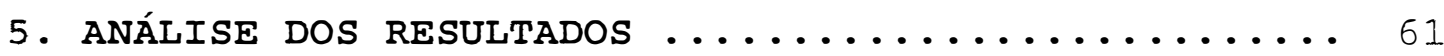

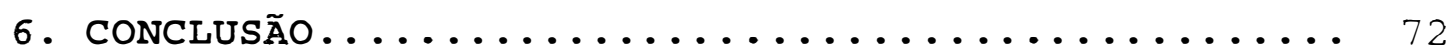

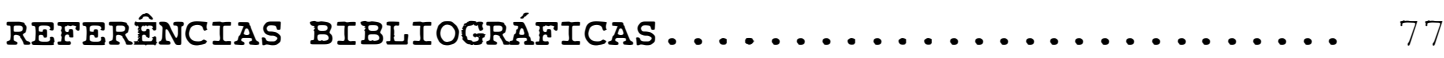

APÊNDICE 1: Especificação normal-truncada e meio-

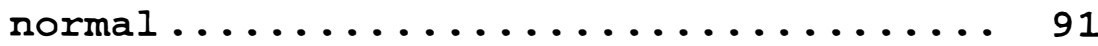

APÊNDICE 2: Estimativa dos parâmetros da função de produção de fronteira estocástica com especificação normal-truncada para uj... 98

APÊNDICE 3: Estimativa da eficiência técnica de cada

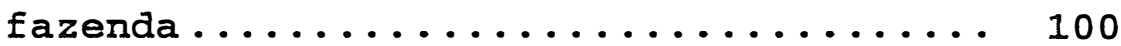

APÊNDICE 4: Cálculo da eficiência técnica média.... 105

APÊNDICE 5: Estatísticas descritivas das variáveis...107 


\section{IISTA DE FIGURAS}

1. Diagrama das medidas de eficiência

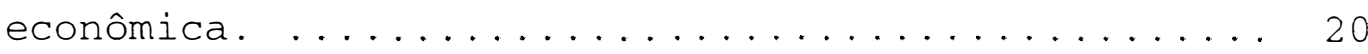

2. Eficiência técnica baseada na função de

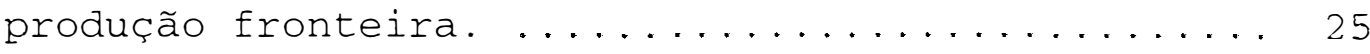

3. Função de produção de fronteira

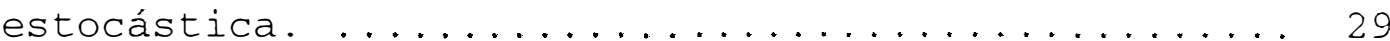

4. Distribuição de freqüência da eficiência

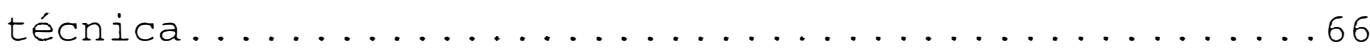




\section{LISTA DE TABELAS}

1. Média da área explorada e utilização da mão-de-obra nas regiões analisadas

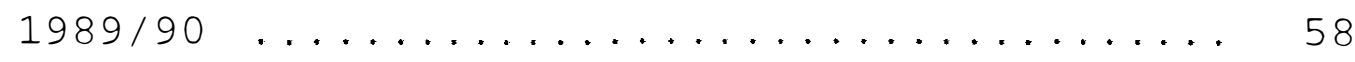

2. Número de agricultores que utilizam práticas agrícolas selecionadas 1989/90....

3. Estimativa dos parâmetros da função de produção Cobb-Douglas e da fronteira de produção estocástica Cobb-Douglas para amostra de agricultores comerciais

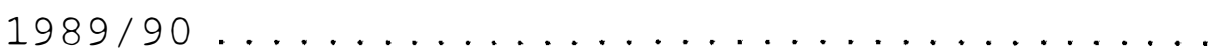

4. Distribuição de Ereqüência da

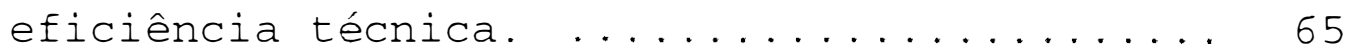

5. Estimativa dos parâmetros do modelo TOBIT com as variáveis: experiência, escolaridade, rádio, extensão pública e

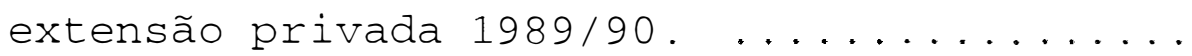

6. Estimativa dos parâmetros do modelo TOBIT com as variáveis: experiência, escolaridadel, rádio, extensão pública, extensão privada $1989 / 90 \ldots \ldots \ldots \ldots$ 
7. Estimativa dos parâmetros da fronteira de produção estocástica Cobb-Douglas para amostra de agricultores comerciais

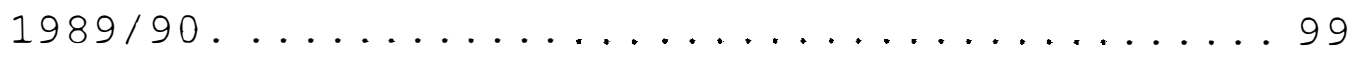

8. Estimativa de $u_{j}$ e da eficiência técnica por fazenda. ..................... 101

9. Estatísticas descritivas das variáveis utilizadas. ................... 108 


\title{
FRONTEIRA DE PRODUÇÃO ESTOCÁSTICA E EFICIÊNCIA TÉCNICA NA AGRICULTURA
}

\author{
Autor: Júnia Cristina Péres Rodrigues da Conceição \\ Orientador: Prof. Dr. Paulo Fernando Cidade de Araújo
}

\section{RESUMO}

O presente trabalio objetiva estimar a eficiência técnica de uma amostra de produtores representantes da agricultura comercial brasileira. A escolha do segmento moderno da agricultura é especialmente importante quando se considera sua participação ativa no processo de modernização da agricultura.

Para a estimação da eficiência técnica foi utilizado o modelo de função de produção de fronteira estocástica que permite, além da estimativa da eficiência técnica média, a estimativa da eficiência técnica de cada fazenda.

A eficiência técnica média estimada foi de 73,08\%. Embora este seja um nível relativamente alto, sua implicação para fins de política agrícola é que ainda há possibilidade de aumentar a produtividade através da melhoria da eficiência técnica. A eficiência técnica em cada fazenda varia no intervalo de 41,47\% a 93,09\%. 
Aproximadamente $52 \%$ dos produtores registram níveis de eficiência técnica entre 75\% e $90 \%$.

Resultado importante é o fato de que 76\% das variações nos níveis de produção dos produtores da amostra estão associados a ineficiência.

No cenário atual, onde a competitividade passa a ser insistentemente perseguida, a constatação da existência de ineficiência técnica entre produtores representativos da agricultura moderna no país é muito importante. Além de gerar e divulgar novas tecnologias fazse necessário esforço adicional para que as inovações tecnológicas sejam usadas de forma eficiente.

O presente trabalho investiga também o papel das variáveis educação, extensão pública, extensão privada, experiência do agricultor e fontes alternativas de informação técnica sobre os níveis observados de eficiência.

Os resultados indicam que as variáveis mais importantes na explicação da eficiência técnica são experiência, extensão privada e fontes alternativas de informação (rádio).

A significância da variável experiência reforça a argumentação, explicitada na literatura do learning by doing. Isto é, o aprender fazendo é uma fonte importante na aquisição/prática de novos conhecimentos.

A importância da extensão privada também é coerente, principalmente quando se considera que este tipo de serviço aumenta rapidamente com o desenvolvimento 
agrícola e é mais especializado em transferência de tecnologia do que a extensão pública.

No Brasil, em especial nas regiões CentroOeste, Sudeste e Sul, a extensão privada tem desempenhado papel fundamental na adoção de novas tecnologias, principalmente entre os produtores voltados para o mercado.

Finalmente, vale destacar a significância estatística das fontes alternativas de informação técnica (rádio) na explicação dos níveis de eficiência. Esse é um caminho ainda pouco explorado para fins de politicas públicas evidenciando o poder que a comunicação de massa pode desempenhar. 


\section{STOCHASTIC FRONTIER PRODUCTION AND TECHNICAL EFEICIENCY IN AGRTCUT.TURE.}

Author: Júnia Cristina Péres Rodrigues da Conceição Adviser: Prof. Dr. Paulo Fernando Cidade de Araújo

\section{SUIMIMARY}

The main objective of this dissertation is to estimate technical efficiency for a sample of commercial farmers in Brazil. The choice of the modern segment of farming is important because this segment has, and also will have, an effective role to perform in the modernization process of the Brazilian agricultural sector.

In order to estimate technical efficiency it was used the stochastic frontier production function. This model provides, in addition to the average technical efficiency, the technical efficiency for each individual farmer of the studied sample.

The results derived from the econometric estimation of the stochastic frontier production function indicate that average technical efficiency was 73,08\%. Although it may be considered a relatively high index, its agricultural policy implication is that still remains the possibility of increasing total factor productivity by improving technical efficiency. 
Technical efficiency index ranges from 41, 47\% to $93,09 \%$ for the farms in the sample, and $52 \%$ of these farms have technical efficiency index between $75 \%$ and $90 \%$.

An important result is that $76 \%$ of the total variation in farm output may be explained by technical inefficiency .

In a second step analysis, relationships between technical efficiency and some human capital variables, as education, public extension, private extension, farm experience and alternative sources of information, were examined. This analysis relied on a Tobit regression model. The results show that the most important variables in explaining technical efficiency were experience, private extension and alternative sources of information (radio).

The result concerning experience suggest that farmers with more experience have higher level of technical efficiency. The positive and statistically robust relationship between private extension and technical efficiency supports the notion that farmers more exposed to contacts with private extension services have an efficiency advantage over the other farmers. This result is consistent with the fact that this kind of services increase during the agricultural development process. Also they are much more specialized in technology transfer than public extension. This is especially true in modern agricultural regions.

In Brazil, especially in the Center-west, South and Southeast regions, the private extension services 
are likely to play an important role in the technology diffusion process.

Finally, an important policy implication emerging from the second step analysis is the statistically significant connection between technical efficiency and alternative sources of information. 


\section{INTRODUÇÃO}

Existe considerável concordância de que uma boa estratégia de desenvolvimento econômico depende criticamente da promoção da produtividade e do crescimento do setor agrícola. Para que o setor agrícola possa desempenhar as clássicas funções de fornecer alimentos, matérias-primas e mão-de-obra para o setor industrial e gerar divisas e recursos para a formação de capital na economia os ganhos de produtividade são, sem dúvida, uma questão fundamental (Hayami \& Ruttan, 1985; Kuznets, 1966; Schultz, 1964).

Neste sentido, o grande desafio que se colocava para o setor agrícola brasileiro, em meados da década de sessenta, era o da modernização, já que até então - crescimento da produção era obtido basicamente através da expansão da área cultivada e/ou pelo aumento da mão-de-obra utilizada no processo produtivo (Alves e Pastore, 1977).

A partir deste contexto, foi adotado no Brasil, principalmente a partir de meados da década de 60, o modelo de modernização do setor agrícola que prevaleceria nas décadas seguintes e que foi responsável pela transformação da agricultura brasileira. Segundo Alves e Pastore (1980), o objetivo que se pretendia atingir era o 
aumento da produção no curto prazo através, basicamente, do aumento da produtividade. No decorrer deste processo foram utilizados instrumentos de política como crédito rural, preços mínimos, assistência técnica e pesquisa. O modelo de modernização consistiu de mudanças tecnológicas que privilegiaram a utilização de insumos e fatores de produção modernos, como fertilizantes, defensivos, herbicidas, sementes melhoradas, tratores e implementos (silva et al., $1990\}$.

Este modelo tradicional de política agrícola, baseado principalmente no fornecimento de crédito e na garantia de preços mínimos, começou a mostrar sinais de esgotamento no final da década de oitenta, com a drástica redução de gastos orçamentários destinados aos programas de suporte à agricultura (Barros, 1998).

Na realidade, surge no início da década de noventa um novo ambiente institucional, com uma economia liberalizante e aberta aos mercados internacionais, passando a priorizar o desenvolvimento de novos mecanismos, em substituição à atuação intervencionista do governo, seja no fornecimento de crédito, no gerenciamento de riscos de preços ou na política de comercialização.

Este novo cenário tem impacto direto sobre a agricultura e esta passa a ter pela frente um novo desafio: a obtenção da eficiência no processo produtivo. Neste sentido, identificar ganhos potenciais de produtividade advindos do uso mais eficiente da tecnologia existente é hoje uma questão fundamental. 
A eficiência econômica é entendida como um processo da produção em que os custos são minimizados, dados os preços dos fatores (eficiência alocativa) e, ao mesmo tempo, a produção ocorre na fronteira tecnológica (eficiência técnica). Isto é, a eficiência econômica é uma combinação das eficiências técnica e alocativa. Vale ressaltar que um dado processo produtivo pode ser eficiente do ponto de vista alocativo, mas não do ponto de vista técnico, ou vice-versa. Em nenhum desses dois casos ter-seia obtido a eficiência econômica.

A presença de ineficiência técnica significa que o produto pode ser aumentado sem a necessidade de aumento no uso de insumos e sem a necessidade de introdução de novas tecnologias. Na realidade, a presença de ineficiência técnica significa que a tecnologia não está sendo explorada em toda a sua plenitude. Se esse for o caso, estudos empíricos são necessários para a determinação da magnitude de ganhos que podem ser obtidos na produção agrícola com a tecnologia atual.

Logo, no caso desses ganhos serem

substantivos, uma implicação para política econômica é que será mais efetivo aumentar a produção agrícola, no curto prazo, concentrando esforços na melhoria da eficiência técnica do que na introdução de novas tecnologias.

Segundo Alves (1993) a saída para o setor comercial da agricultura brasileira, dadas as limitações existentes, sensivelmente agravadas na década de noventa, está na busca/conquista de maior eficiência. O aumento da 
eficiência no processo produtivo poderá incrementar a competitividade do setor nos mercados externos.

Neste cenário, o estudo sobre eficiência técnica de um grupo de produtores representativo da agricultura comercial brasileira se justifica, principalmente por duas razões. A primeira refere-se ao próprio questionamento do processo de modernização em uma dimensão pouco explorada empiricamente, qual seja, verificar se os produtores que efetivamente participaram desse processo o fizeram de forma eficiente. Essa verificação poderá apontar ganhos potenciais ainda não detectados e fundamentais para o aumento da produtividade. A segunda razão refere-se ao fato de, uma vez estimada a eficiência técnica de cada fazenda, é possível identificar a magnitude do ajuste necessário pelo qual o setor deverá passar. Isto é, caso seja constatado que um grande número de produtores produz com níveis de eficiência técnica abaixo da média, ter-se-á uma evidência da necessidade de um forte e rápido ajuste, sob pena desses produtores não sobreviverem no médio prazo.

No contexto atual, onde ganhos de produtividade são fundamentais para a garantia de competitividade da agricultura brasileira, este trabalho poderá contribuir também para a identificação de algumas estratégias de política agrícola. Se, por exemplo, os resultados evidenciarem baixa eficiência técnica, deverá ser dada prioridade a melhoria do processo de difusão de tecnologia, de tal forma que ela seja utilizada em toda a sua potencialidade. Por outro lado, a constatação de um elevado e uniforme nível de eficiência entre as fazendas 
indica que a possibilidade de exploração da tecnologia existente está praticamente exaurida, o que leva à recomendação de investimentos em pesquisa.

A literatura recente tem apresentado avanços na obtenção das estimativas de eficiência a partir da estimação de funções de produção utilizando, principalmente, a função de produção fronteira. A modelagem econométrica de funções de produção fronteira é um instrumento útil para a determinação de medidas de eficiência das firmas e se aproxima do conceito de função de produção usualmente encontrado nos livros textos de microeconomia. Ou seja, a produção máxima que pode ser obtida a partir de um determinado conjunto de insumos, com a tecnologia disponível às firmas. Vale ressaltar que, apesar desta metodologia ter sido muito discutida internacionalmente, no Brasil existem poucos trabalhos que a utilizam.

Entre esses trabalhos pode-se citar 0 trabalho de Taylor, Drummond \& Gomes (1986) analisando eficiência técnica e econômica de um grupo de produtores através da estimativa de uma função de produção de fronteira determinística; o de Taylor \& Shonkwiller (1986) estimando uma função de produção de fronteira estocástica a partir dos dados de Taylor, Drummond \& Gomes.

Estes autores tinham como objetivo verificar se agricultores que participaram do programa de assistência técnica- PRODEMATA- eram mais eficientes do que aqueles que não participaram. Os agricultores eram da região da zona da 
Mata do Estado de Minas Gerais e caracterizados como tradicionais.

Tupy (1996) utilizou a metodologia de função fronteira para estimar a eficiência econômica de uma amostra de produtores de frangos no Brasil. Nove empresas, representando, aproximadamente $20 \%$ da produção brasileira de frangos de corte, foram analisadas entre janeiro de 1995 e abril de 1996. As estimativas de eficiência econômica foram obtidas pelo método de fronteira estocástica. Elevados niveis de eficiência foram registrados, entre 93\% e 100\%. Gomes (1996) utilizou uma função de produção CobbDouglas de fronteira deterministica, para estimar a eficiência técnica de pequenos produtores de tomate no perímetro irrigado de Senador Coelho, em Petrolina, Estado de Pernambuco.

É exatamente no contexto de eficiência técnica que se situa o presente estudo. Ele objetiva determinar a eficiência técnica de 108 agricultores, em regiões de agricultura moderna do Brasil.

Além da estimativa da eficiência técnica, uma questão não menos importante é a possível identificação de variáveis que possam explicar variações nos níveis de eficiência. Na literatura sobre o assunto, diversos autores têm procurado investigar o papel desempenhado pelas diferentes formas de capital humano. O presente trabalho se propõe também a investigar esse papel. 


\subsection{Hipóteses}

Atualmente, quando os ganhos de produtividade precisam ser perseguidos, e considerando que a modernização da agricultura brasileira foi responsável por mudanças significativas na estrutura produtiva do segmento comercial do setor, a grande questão que se coloca é saber até que ponto os agricultores que se beneficiaram desse processo o fizeram de forma eficiente. Explicitamente, as hipóteses a serem testadas são:

i) pode-se aumentar a produtividade total dos fatores no segmento representativo da agricultura comercial brasileira pela melhoria da eficiência técnica. Isto é, os agricultores não estão conseguindo explorar plenamente as potencialidades da tecnologia empregada ;

ii) o nível de eficiência técnica não é uniformemente distribuído entre os agricultores; e,

iii) variáveis representativas de capital humano, especificamente, educação formal, extensão pública e particular, experiência e acesso a informação têm efeitos positivos sobre os níveis de eficiência técnica. 


\subsection{Objetivos}

o presente estudo objetiva estimar o nível de eficiência técnica de um grupo de agricultores modernos no Brasil, bem como verificar a influência de algumas formas de capital humano sobre os níveis de eficiência encontrados. Especificamente, pretende-se:

i) estimar uma função de produção de fronteira estocástica representativa da agricultura moderna/comercial;

ii) estimar a eficiência técnica em termos médios e de cada fazenda; e,

iii) testar a influência das variáveis, educação, experiência, informação e contatos com os serviços de extensão sobre os níveis de eficiência encontrados.

\subsection{Estrutura da Pesquisa}

Além desta introdução, o capítulo 2 é dedicado à revisão de literatura. Inicialmente, é realizada uma breve retrospectiva sobre as fontes de crescimento da agricultura brasileira, enfatizando a mudança ocorrida na condução da política agrícola a partir do final da década de 80 e, mais intensamente, na década de 90. Em seguida, 
discute-se a modelagem econométrica de funções de produção fronteira e aplicações empíricas dos modelos utilizados.

No capítulo 3 é apresentado o modelo teórico da pesquisa. A metodologia, incluindo especificações dos modelos econométricos e definição das variáveis, é apresentada no capítulo 4. No capítulo 5 são discutidos os resultados encontrados. E, finalmente, no capítulo 6 aparecem as principais conclusões da tese. 


\section{REVISÃO DE IITERATURA}

\subsection{Fontes de crescimento na agricultura brasileira: expansão da área, produtividade e eficiência.}

Até a década de 60, a maior fonte de crescimento da produção agrícola no Brasil foi a expansão da área cultivada e do emprego. Segundo Alves e Pastore (1977), na década de 1950, 70\% do aumento da produção agrícola eram explicados pela expansão da área cultivada e $30 \%$ pelo aumento da produtividade da terra. No que se refere ao aumento explicado pela expansão do uso de mão-deobra, 60\% foram em função de acréscimos de unidades do fator trabalho e $40 \%$ decorrentes do aumento de sua produtividade. No período 1950/55, a expansão do emprego chegou a contribuir com $78 \%$ desse crescimento.

Este fato é também evidenciádo por Patrick (1975) que, utilizando uma versão modificada do modelo shift-share, decompõe, para o período 1959/61 a 1967/69, as fontes de crescimento da agricultura em efeito área, rendimento e localização. O autor conclui que, naquele 
período, o efeito área foi o mais importante para o crescimento da produção.

Barros, Pastore e Rizzieri (1977) afirmam que este comportamento se estende até a década de 70, com o crescimento da agricultura sendo caracterizado principalmente pela expansão da fronteira agrícola.

De fato, estendendo a análise de Patrick (1975) para o período 1967/1979, Cunha e Daguer (1982), observaram que o efeito área foi a principal fonte de variação da produção. O efeito rendimento foi o componente mais importante para a explicação da taxa de crescimento da produção de apenas seis culturas.

Vale ressaltar, porém que, a partir de meados dos anos 60, ficava claro que a produtividade do setor precisava crescer e que seria falacioso acreditar que isto poderia ocorrer via utilização de um suposto estoque de conhecimentos existentes nas instituições públicas de pesquisa agrícola. Também parecia claro que a pesquisa agrícola tinha especifidades locais, o que implica a necessidade de grandes investimentos em geração e adaptação de tecnologias agrícolas importadas de outras regiões/países.

Neste sentido, Schuh (1975) procurou mostrar que a modernização seria o caminho a, ser seguido, destacando ainda a importância do fortalecimento das indústrias de bens e insumos agrícolas, da melhoria dos níveis educacionais no meio rural e do fortalecimento das instituições de pesquisa agrícola. 
Tornou-se também evidente 0 papel da agricultura no processo de desenvolvimento do país. Em um primeiro momento, foi atribuída ao setor a responsabilidade pelo abastecimento interno e pela geração de excedentes exportáveis. Desempenhar estas funções exigiu um grande esforço rumo à modernização da agricultura, que passou a necessitar de ganhos crescentes de produtividade, além, é claro, de uma alocação mais eficiente dos recursos disponíveis.

O aumento da produtividade passou a ser perseguido e para tanto instrumentos de política agrícola, como crédito rural, preços mínimos, programas de assistência técnica e de pesquisa passaram a fazer parte da agenda de prioridades do país. A ênfase da política agrícola, desde então, concentrou-se basicamente na institucionalização do crédito subsidiado, no incentivo ao uso de fertilizantes e outros insumos modernos e na concessão de privilégios fiscais.

Como conseqüência da adoção desses instrumentos, os fatores indutores do crescimento da produção agropecuária foram, especialmente, o aumento da utilização de insumos modernos, os resultados da pesquisa agronômica e mudanças na composição da produção.

O aumento da utilização de insumos modernos foi, em grande parte, viabilizado pela política de crédito rural. Até 1980 o setor agrícola contou com uma oferta ilimitada de créditos. Além disso, a agricultura contou também com forte subsídio implícito na taxa de juros o que fez com que a política de crédito fosse o principal 
instrumento da modernização. De fato, a instituição em 1965, de um sistema de crédito com recursos ilimitados e taxas de juros reais negativas fez com que muitos pacotes tecnológicos fossem adotados pelos agricultores que tinham acesso aos mercados financeiros. Isso ocorreu principalmente na década de 70 e promoveu a rápida, porém parcial, modernização do setor agrícola.

De fato, Araújo (1983), Barros (1979) e Munhoz (1982) mostraram que o crédito agrícola subsidiado foi, durante as décadas de 60 e de 70, o principal determinante do crescimento da produção. No entanto, este instrumento apresentou um lado perverso com relação a distribuição dos recursos entre produtores, produtos e regiões. Em outras palavras, estimulou uma forte concentração em fazendas comerciais e nas regiões sul e Sudeste (Araújo, 1983).

No que respeita à diversificação de culturas, a mais notável mudança ocorreu na composição da produção na direção de culturas caracterizadas por demanda em forte expansão no comércio internacional, com especial destaque para a soja. Além disso, a mecanização, a pesquisa agrícola e o uso de insumos químicos foram fundamentais para a expansão da fronteira agrícola, particularmente em direção ao centro-Oeste, a partir da segunda metade dos anos 70 .

Os esforços para a institucionalização de um sistema de pesquisa agropecuária, na década de 70, foram responsáveis pela introdução de novas variedades e implantação de novos sistemas de produção contribuindo, 
inclusive, para a utilização de ecosistemas até então inapropriados para a atividade agrícola.

Segundo Barros (1983) fica evidente que a estratégia brasileira de modernização agrícola, no período 1960-80, baseou-se, em quatro pontos fundamentais: expansão dos programas de crédito subsidiado, elevação dos gastos em extensão rural e pesquisa, maior abertura ao comércio internacional e prioridade ao setor de insumos modernos (tratores, fertilizantes, inseticidas, e herbicidas).

Foi em função desses fatores que os ganhos de produtividade passaram a ser uma importante fonte de crescimento da produção, especialmente das culturas ditas modernas. Este fato é verificado, mais intensamente, na década de 80, onde os ganhos de produtividade foram determinantes do aumento da produção agrícola. Segundo Gasques e Villa Verde (1990), a taxa anual de crescimento da produtividade agrícola, no período 1981/88, foi da ordem de 1,41\%, representando $43 \%$ do crescimento do produto real.

Este fato é também constatado por Ferreira (1991) que, utilizando uma versão modificada do modelo de decomposição estrutural diferencial (shift-share), analisou as fontes de crescimento da agricultura brasileira no período $1977 / 78$ a $1987 / 88$. Os resultados encontrados pelo autor mostram a crescente importância dos ganhos de produtividade, que passam a ser a principal fonte de crescimento na década de 80.

Em contrapartida, a politica de crédito rural sofreu mudanças substanciais nos anos 80 . A direção 
geral foi no sentido de uma política mais restritiva no que se refere ao volume de recursos e encargos financeiros.

Por outro lado, a política de preços mínimos incorporou, na década de 80, alterações que a tornaram um dos principais instrumentos de política agrícola. As mudanças mais significativas foram a correção do preçobase, o estabelecimento da plurianuidade e a criação dos preços de intervenção. Essas alterações fizeram parte da estratégia governamental de compensar a redução do subsídio via crédito rural.

Apesar da alteração dos mecanismos de intervenção no setor frente as dificuldades dos ajustes econômicos, um resultado importante da política de modernização da agricultura foi a transformação da composição/estrutura do produto agropecuário e de sua base tecnológica.

Acontece que este processo acabou por favorecer determinados produtos e regiões, estabelecendo um padrão de modernização desigual. A modernização fortaleceu principalmente o segmento moderno da agricultura, altamente tecnificado, que utiliza técnicas sofisticadas de produção. $\mathrm{Na}$ realidade, continua existindo, entre nós, um segmento de agricultores tradicionais, que não participa ativamente desse processo. Esta constatação e sua discussão detalhada foram objeto de vários estudos como os de veiga (1991), Alves \& Contini (1992), Barros, Pastore \& Rizzieri (1976).

Como salienta Veiga (1991), o processo de modernização ocorreu em condições de elevada ineficiência técnica e alocativa. Segundo o autor, a produção agrícola, 
em 1970, atingiu somente 45\% da sua produção potencial, ou seja, daquela que poderia ser obtida com os mesmos recursos e a mesma tecnologia. E este percentual foi mais baixo justamente nas regiões de mais intensa modernização (Cunha e Dagner, 1982). Entre as possíveis causas dessa ineficiência da modernização parece estar incluída a aplicação do subsídio, como instrumento-chave do processo de modernização.

Essa possivel ineficiência é corroborada por Arnade (1992) que, ao analisar produtividade e mudança técnica na agricultura no período de 1968-1987, sugere que a ineficiência era decorrente dos subsídios implícitos no crédito rural. Segundo o autor, no período de 1968 a 1979 , a ineficiência praticamente anulou os efeitos de mudança técnica e economias de escala na agricultura, o que levou a uma produtividade total dos fatores negativa.

Desde os últimos anos da década de 80, reduziram-se drasticamente as aplicações públicas fiscais e financeiras no setor agrícola (Barros, Meires \& Malheiros, 1993 e Gasques \& Villa Verde, 1991 e 1995). É que os dois principais instrumentos de política agrícola - crédito rural e preços mínimos - foram severamente sacrificados.

$\mathrm{Na}$ realidade, a partir da chamada "Nova República", em 1985, já se tinha desenhado um arcabouço de uma política agrícola mais voltada para' o mercado. A motivação para tal reformulação estava no esgotamento do modelo de substituição de importações, cujas âncoras foram: i) taxa de câmbio sobrevalorizada; ii) política comercial criando barreiras de proteção à indústria; iii) controle de 
preços agrícolas para conter o custo de vida; e, iv) créditos para aumentar a demanda por insumos industriais e estimular o crescimento da produção agropecuária.

A falência financeira e operacional do Estado e a globalização dos mercados decretaram o esgotamento do processo. Segundo Barros (1998), a manutenção do crescimento da agricultura passou a ser concebida com base em novo tripé: il racionalização do gasto público com dispêndio seletivo voltado para a produtividade e bem-estar no campo; iil liberalização comercial interna e externa; $e$, iiil maior realismo cambial.

A década de 90 apresenta, portanto, um novo desafio à agricultura brasileira, inclusive aos agricultores modernos, face às restrições decorrentes da abertura econômica e da crise fiscal. A abertura comercial é compatível com a menor participação do Estado em certas políticas, como abastecimento, gerenciamento de riscos e financiamento. Em compensação, ela acentua a necessidade de maior participação em outras políticas voltadas para o crescimento contínuo da produtividade e, portanto, da competitividade.

Esse desafio é ainda maior quando se constata que no período 1984-87, segundo Arnade (1992) a ineficiência teve um impacto negativo sobre o comportamento da produtividade total dos fatores na agricultura brasileira. O autor, entretanto, utilizou dados de série temporal, agregados para várias culturas. Desta forma, não 
se pode afirmar, com certeza, que tal comportamento seja também verdadeiro para o segmento moderno da agricultura.

Questão importante que se configura na década de 90 é saber se os agricultores comerciais, tecnificados e modernos são, de fato, eficientes. Neste sentido, a possibilidade de identificação do nível de eficiência média e de cada fazenda é, sem dúvida, uma contribuição importante para os formuladores de políticas macroeconômica e agrícola.

O presente estudo trabalha com a hipótese de que $o$ segmento comercial da agricultura brasileira conseguiu ganhos expressivos de produtividade ao incorporar novas tecnologias. Contudo, este segmento pode ainda melhorar seu desempenho através de ganhos de eficiência técnica.

\subsection{Fundamentação teórica sobre fronteiras de produção e medidas de eficiência técnica.}

$\mathrm{Na}$ literatura internacional, as funções de produção fronteira têm sido utilizadas largamente para calcular a eficiência técnica na agricultura. Existem diversas metodologias que permitem obter esta medida de eficiência e, neste sentido, este capítulo se propõe a apresentar algumas delas. Idealmente, as mais importantes.

Existem, basicamente, dois paradigmas sobre como estimar fronteiras. Um usa técnicas de programação matemática; outro emprega técnicas econométricas. A 
principal vantagem da programação matemática ou Data Envelopment Analysis (DEA) é que nenhuma forma funcional explícita é imposta aos dados. Contudo, a fronteira estimada pode conter vieses se os dados utilizados possuírem ruídos estatísticos. A abordagem econométrica incorpora o erro estatístico, mas impõe uma forma funcional explícita para a função. Além disso, a não ser que dados de painel estejam disponíveis, é necessária também uma pressuposição explícita sobre a distribuição do termo do erro que representa a ineficiência.

Neste capítulo pretende-se discutir somente a abordagem econométrica, já que esta será utilizada para estimar a eficiência técnica. Desenvolvimentos recentes da abordagem de programação matemática são discutidos em Seiford \& Thrall (1990).

O ponto inicial para qualquer discussão sobre fronteira e obtenção das medidas de eficiência é o trabalho de Farrell (1957), que forneceu definições e um arcabouço computacional tanto para a eficiência técnica quanto para a alocativa, partindo do conceito de fronteiras determinísticas não paramétricas.

Farrell introduziu o conceito de eficiência considerando uma firma hipotética que utiliza dois insumos $x_{1}$ e $x_{2}$ para produzir o produto $y$. Por simplificação, assumiu que a firma produzia com retornos constantes a escala, de tal forma que fosse possível escrever $1=f\left(x_{1}, x_{2}\right)$, ou seja, a fronteira tecnológica pode ser caracterizada por uma isoquanta unitária UU' (Figura 1). 


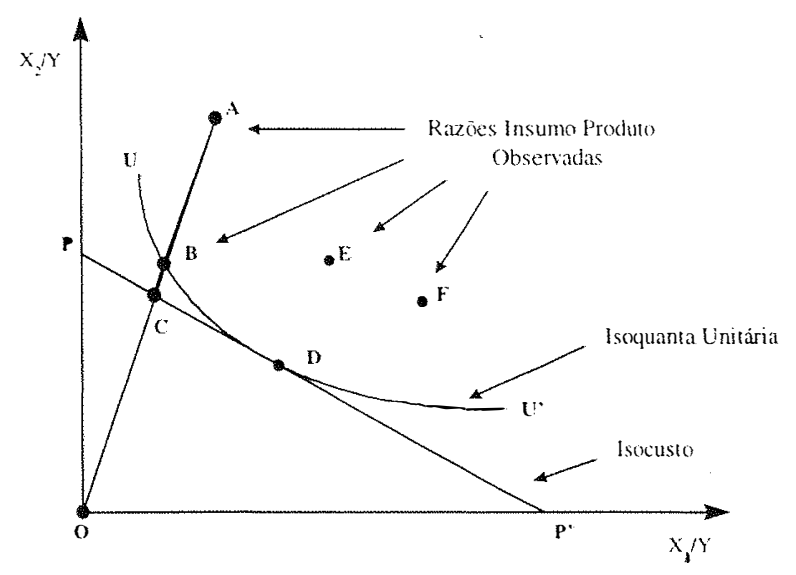

Figura 01: Diagrama das Medidas de Eficiência Econômica Fonte: Battese (1992) e Schmidt (1986)

Os eixos horizontal e vertical, na Figura 1, mostram as razões insumo-produto para $x_{1}$ e $x_{2}$, respectivamente. A isoquanta unitária UU' define as razões insumo-produto associadas ao uso mais eficiente dos insumos para produzir o produto y (Battese, 1992). Qualquer desvio das razões insumo-produto definidas pela isoquanta UU' está, portanto, associado à ineficiência técnica.

Sob este cenário, as firmas que operam ao longo da isoquanta, ou seja, $B$ e $D$, são tecnicamente eficientes. Firmas que operam acima da isoquanta são ineficientes em relação às que operam na isoquanta e seus níveis de eficiência são medidos pela relação entre as razão insumo-produto eficiente (sobre a isoquanta) e a razão insumo-produto observada. 
Se a firma estiver usando $\left(x_{1}^{0}, x_{2}^{0}\right)$ para produzir $y^{0}$, ela estará no ponto $A$ na figura 1 , representado por $\left(x_{1}^{0} / y^{0}, x_{2}^{0} / y^{0}\right)$ (por definição, a firma não pode ficar abaixo de $U^{\prime}$ ). Assim, a razão $O B / O A$ mede a eficiência técnica como a razão dos insumos necessários para produzir $y^{0}$ em relação aos insumos realmente utilizados para produzir $y^{0}$, dado o mix de insumos. Então 1-(OB/OA) mede a ineficiência técnica, ou seja, o montante pelo qual $x_{1}$ e $x_{2}$ poderiam ser reduzidos, sem que houvesse redução do produto $y$ (Schmidt, 1986). A reta $P P^{\prime}$ representa a razão dos preços dos insumos. Então, a razão $O C / O B$ mede a eficiência alocativa, já que o custo no ponto $\mathrm{C}$ é o mesmo do ponto alocativamente eficiente $D$, e é menor do que o tecnicamente eficiente, mas alocativamente ineficiente ponto $B$. Finalmente, OC/OA mede a eficiência total (eficiência econômica).

Certamente, a isoquanta unitária não é observável. Logo, deve ser estimada a partir de uma amostra de observações. A análise de Farrell é não-paramétrica no sentido de que o autor apenas constrói, a partir de técnicas de programação linear, a disposição das razões de insumo-produto observadas. Este procedimento não é baseado em nenhum modelo explícito de fronteira. A análise de Farrell (1957) foi estendida e aplicada por Farrell \& Fieldhouse (1962), Seitz (1970), 1971), Todd (1971), Afriat (1972), Dugger (1974) e Muller (1976). 
A vantagem deste tipo de análise é que nenhuma forma funcional é imposta aos dados. A desvantagem principal é que a pressuposição de retornos constantes a escala é restritiva, e sua extensão para retornos não constantes à escala não é direta ${ }^{1}$.

Embora a análise não-paramétrica de Farrell tenha adquirido inúmeros seguidores, sua abordagem denominada fronteiras determinísticas paramétricas mostrouse mais adequada. É que ela tem a vantagem de estimar a fronteira a partir de uma forma matemática.

Aigner \& Chu (1968) foram os primeiros a seguir esta segunda abordagem de Farrell. Eles especificaram uma fronteira de produção Cobb-Douglas, onde todas as observações deveriam estar situadas na Eronteira ou abaixo dela.

Tal modelo pode ser escrito da seguinte forma :

$$
\begin{aligned}
& \ln y=\ln f(x)-u=\alpha_{0}+\sum_{i=1}^{n} \alpha_{i} \ln x_{i}-u \\
& u \geq 0
\end{aligned}
$$

Onde :

$y=$ nível de produção;

$f(x)=$ função de produção (representação da tecnologia);

$x=$ insumos utilizados no processo produtivo;

\footnotetext{
${ }^{1}$ Veja Farrell \& Fieldhouse (1962) e Seitz (1971) para maiores detalhes.
} 


$$
\begin{aligned}
& \alpha=\left(\alpha_{0}, \alpha_{1}, \ldots, \alpha_{n}\right)=\text { vetor de parâmetros; } \\
& u=\text { termo do erro }
\end{aligned}
$$

onde o termo de erro $u$ força $y \leq f(x)$. Os elementos do vetor de parâmetros $\alpha=\left(\alpha_{0}, \alpha_{1}, \ldots, \alpha_{n}\right)$ podem ser estimados tanto por programação linear (minimizando a soma dos valores absolutos dos resíduos sujeitos à restrição de que cada resíduo é não-positivol ou por programação quadrática (minimizando a soma dos quadrados do resíduo sujeita à mesma restrição acima). Segundo Aigner \& Chu (1968), a eficiência técnica de cada observação pode ser calculada diretamente a partir do vetor de resíduos, já que u representa a ineficiência técnica.

As principais vantagens da análise paramétrica vis-à-vis a análise não-paramétrica são a habilidade para caracterizar a fronteira tecnológica através de uma forma matemática, e a possibilidade de retornos não constantes à escala (note que $\sum_{i=1}^{n} \alpha_{i}=1$ não é imposto em (1)).

Um problema com este tipo de análise é que as estimativas produzidas não possuem propriedades estatísticas. Isto é, o procedimento de programação matemática produz estimativas sem desvio padrão e razão $t$. Isto ocorre porque não são feitas pressuposições sobre os regressores e o erro na função (1), o que significa dizer que sem essas pressuposições estatísticas não se obtêm resultados de inferência. 
O modelo anterior pode ser adaptado para a análise estatística através de algumas pressuposições. Neste caso, tem-se Fronteiras Estatisticas Deterministicas. Note que o modelo (1) pode ser escrito como:

$$
\begin{aligned}
& y=f(x) e^{-u} \\
& \text { ou } \\
& \ln y=\ln [f(x)]-u
\end{aligned}
$$

onde $u \geq 0$ ( e, portanto, $\left.0 \leq e^{-u} \leq 1\right)$, e onde $\ln [f(x)]$ é Iinear no caso da função Cobb-Douglas (1). No caso do modelo de fronteira determinística definido em (2), a eficiência técnica da firma i é dada por:

$$
T E_{i}=Y_{i} / Y_{i}^{*}=f\left(x_{i}\right) e^{-u_{i}} / f\left(x_{i}\right)=e^{-u_{i}}
$$

onde $Y^{*}$ representa o máximo de produção, para cada nível de insumo $x$.

O termo fronteira implica que a função tem um Iimite para o conjunto de observações possíveis. Desta forma, no caso da função de produção, nenhuma observação pode ficar acima da Eunção de produção fronteira². A figura 2 apresenta a descrição geométrica da função de produção Eronteira.

\footnotetext{
z O inverso é verdadeiro para funções de custo, onde nenhuma observação pode ficar abaixo da função de custo fronteira.
} 


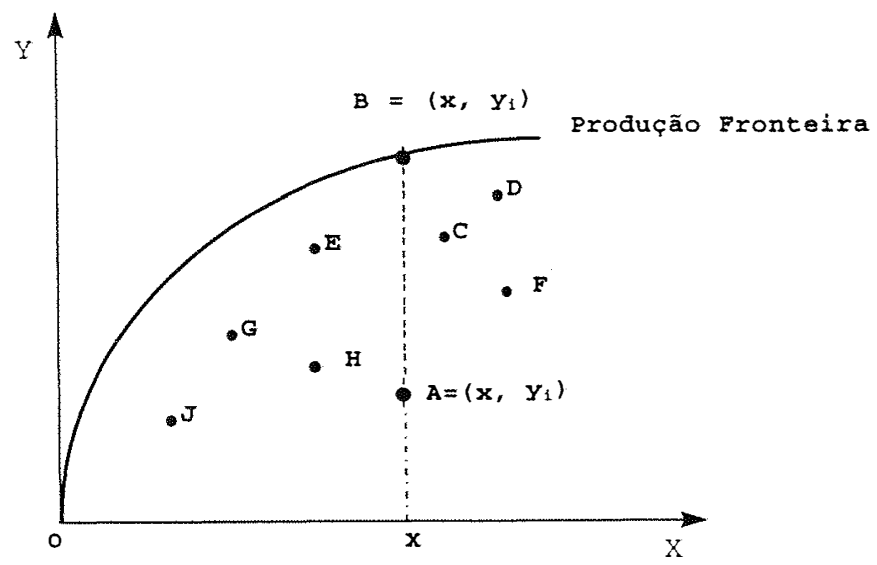

Figura 02: Eficiência técnica baseada na função de produção fronteira

Fonte: Battese (1992).

o que diferencia a função de produção tradicional da função de produção fronteira é, portanto, a restrição descrita anteriormente. Dessa forma, enquanto a estimativa da função de produção permite tanto desvios positivos quanto negativos, a estimativa da função de produção fronteira determinística permite apenas a existência de desvios não-positivos. As relações insumoproduto observadas encontram-se abaixo da fronteira. Isto significa que, para a tecnologia dada, as firmas não alcançaram a máxima produção, sendo, portanto, ineficientes. A medida de eficiência técnica baseada na fronteira é análoga à medida utilizada por Farrell, refletindo a distância entre uma firma e a fronteira. Na figura 2, a eficiência técnica da firma A, por exemplo, é 
dada pela relação entre a produção observada $Y_{A}$, e a produção máxima obtida pela firma B $\left(Y_{\boldsymbol{B}}\right)$.

Questão que merece ser discutida é qual a pressuposição a ser feita sobre $x$ e $u$. A maioria dos trabalhos pressupõe que as observações sobre u são independentemente e identicamente distribuídas e que $x$ é independente de $u$. Vale ressaltar, porém, que um grande número de distribuições para u pode ser especificado.

Aigner \& Chu (1968) não assumiram este modelo explicitamente, embora pareça claro que o tenham assumido implicitamente. Afriat (1972) foi o primeiro a propor este modelo. Propõe uma distribuição beta para $e^{u}$; ademais, que o modelo fosse estimado pelo método da máxima verossimilhança.

Deve ser ressaltado que a escolha da distribuição de $u$ é importante porque as estimativas de máxima verossimilhança dependem fundamentalmente do tipo de distribuição considerada. Diferentes distribuições produzem diferentes estimativas.

Método alternativo de estimação foi proposto por Richmond (1974), com base nos resultados de mínimos quadrados ordinários, usualmente chamado mínimos quadrados corrigidos.

Nos modelos anteriores, a fronteira comum às firmas era determinística, e toda variação no desempenho da firma é atribuída a variações na sua própria eficiência. A noção de fronteira determinística ignora, desta forma, a possibilidade real de o desempenho de uma firma ser afetado 
por: i) fatores completamente fora do controle do produtor/administrador (tais como, problemas climáticos e de queda na oferta de insumos, dentre outros); e, ii) fatores resultantes da ineficiência do administrador. Considerar efeitos de choques externos junto com efeitos de erros de medida e ineficiência em um único termo de erro e classificá-lo como ineficiência é algo bastante questionável.

Esta posição é reforçada quando se considera a existência do ruído estatístico que qualquer análise empírica apresenta. A interpretação usual é que, além dos erros de mensuração das variáveis, a função pode não estar devidamente especificada.

Esses argumentos são considerados no modelo de fronteira estocástica (também chamado modelo de erro composto), desenvolvido por Aigner et al. (1977) e Meeusen \& Van Den Broeck (1977). A idéia essencial do modelo de fronteira estocástica é que o termo do erro é composto de dois elementos. Um componente simétrico, permitindo variações aleatórias da fronteira entre as firmas, e captando os efeitos de erros de medida, outros "ruídos" estatísticos e choques aleatórios fora do controle da firma. Outro, componente unilateral, captando os efeitos da ineficiência em relação a fronteira estocástica.

Este modelo de fronteira estocástica pode ser assim especificado:

$$
y=f(x) e^{(v-u)}
$$


Onde a fronteira de produção estocástica é $y=f(x) e^{(v-u)}$, sendo que $v$ tem distribuição simétrica para captar os efeitos aleatórios de erros de medida e choques exógenos que fazem com que $f(x)$ possa variar entre as firmas e $u$ é o termo do erro unilateral que capta a ineficiência e também faz com que $f(x)$ possa variar entre as firmas. A eficiência técnica relativa a fronteira de produção estocástica é captada pelo componente unilateral do erro $e^{-u}, u \geq 0$. A condição $u \geq 0$ assegura que todas as observações estão situadas na fronteira ou abaixo dela.

A estrutura básica do modelo de fronteira estocástica descrito em (5) é apresentada na figura 3, duas firmas $i$ e j são consideradas. A firma $i$ usa insumos dados pelo vetor $x_{i}$ e obtêm a produção $Y_{i}$, mas a fronteira de produção estocástica $Y_{i}^{*}$ excede o valor da fronteira de produção determinística, $f\left(x_{i} ; B\right)$, ou seja $v_{i}$ neste caso é positivo. A firma $j$, por outro lado, usa insumos dados pelo vetor $x_{j}$ e obtêm a produção $Y_{j}$, sendo a função de produção de fronteira estocástica correspondente $Y_{j}^{*}$, inferior à fronteira determinística $f\left(x_{i} ; B\right)$. Ou seja, neste caso $v_{j}$ é negativo. Em ambos os casos os níveis de produção observados são menores do que os respectivos níveis de produção determinados pela fronteira estocástica. Mas os níveis de produção determinados pela fronteira estocástica podem estar acima ou abaixo do nível de produção 
determinado pela fronteira deterministica; isso vai depender dos valores da variável aleatória v.

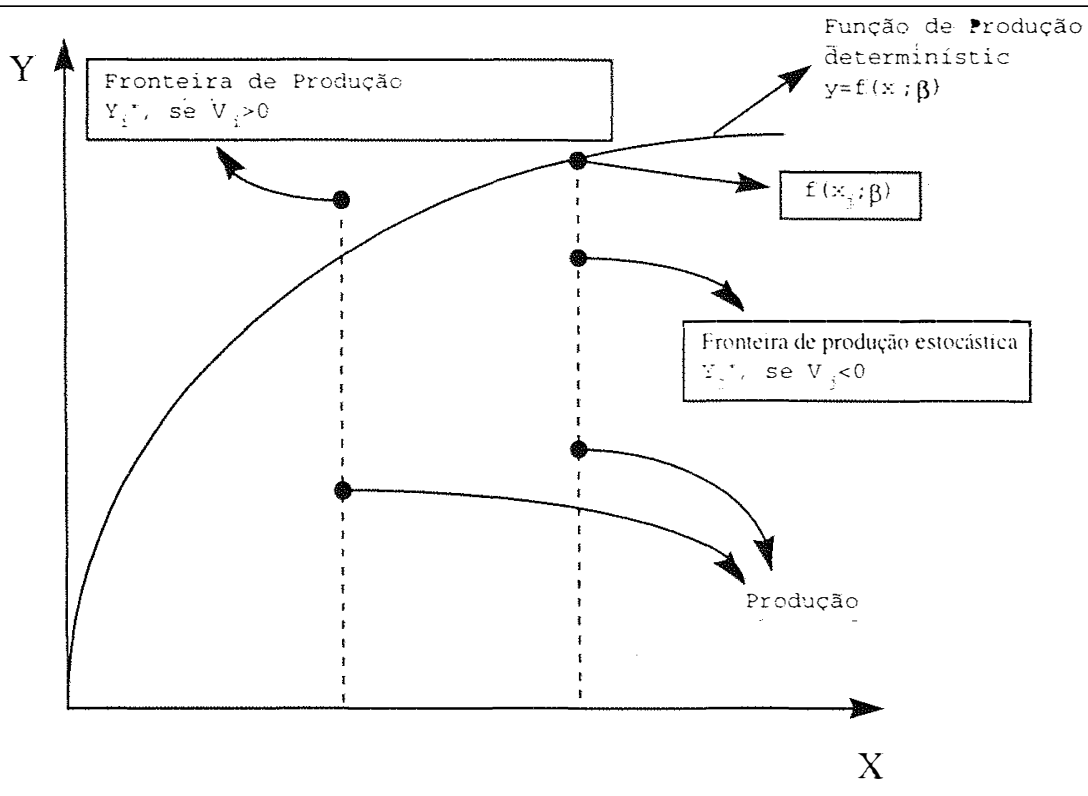

Figura 3: Função de produção fronteira estocástica

Fonte: Battese, 1992

É interessante observar que quando $v=0, \quad$ o modelo (5) se transforma em modelo de fronteira determinística. Quando $u=0$, o modelo não é mais de fronteira e sim modelo de produção média, estimado por mínimos quadrados ordinários.

Conhecidas as pressuposições do modelo de fronteira estocástica, a inferência sobre seus parâmetros pode ser baseada nos estimadores de máxima verossimilhança.

A eficiência técnica de uma firma individual é definida em termos da razão produção observada-produção de fronteira correspondente. Desta forma, a eficiência técnica da firma i no contexto da função de fronteira 
estocástica é a mesma expressão do modelo de fronteira determinística, isto é, $T E=e^{-1}$, ou seja:

$$
T E_{i}=Y_{i} / Y_{i}^{*}=f\left(x_{i}\right) e^{u_{i}-u} / f\left(x_{i}\right) e^{v_{i}}=e^{-u_{i}}
$$

A determinação da eficiência técnica de firmas individuais associada à função de produção fronteira estocástica, definidas por $T E_{i}=e^{-n_{t}}, i=1,2,3, \ldots n$ não era possível de ser estimada até o aparecimento do trabalho de Jondrow et al. (1982). Esta era uma grande desvantagem do modelo de fronteira estocástica vis-à-vis o de fronteira determinística. O trabalho de Jondrow et al. (1982) propôs um método de decomposição do termo do erro $\varepsilon$, em seus dois componentes, $u$ e $v$, a partir da expectativa condicional da variável aleatória $u$ dado o valor da variável aleatória $\varepsilon=v-u$, já que $\varepsilon$ era observável. Esta expectativa foi derivada para os casos em que os u's tinham distribuições meio normal e exponencial.

Outro aspecto a esclarecer refere-se ao método de obtenção da eficiência técnica. A metodologia descrita anteriormente utiliza o conceito de Timmer (1971), ou seja, a medida de eficiência técnica é dada pela razão entre a produção estimada e a produção fronteira. A medida de eficiência, introduzida por koop(1981) e posteriormente por Koop \& Diewert(1982), é a razão entre os níveis de insumos necessários para a produção tecnicamente eficiente e o nível de insumos utilizado. Esta metodologia foi 
aplicada por vários autores, dentre eles Bravo-Ureta \& Pinheiro (1997), Bravo-Ureta \& Rieger (1991). Battese (1992) ressalta que as medidas de eficiência de Timmer e Koop somente são equivalentes se a função de produção fronteira tiver retornos constantes a escala.

No presente estudo é utilizada a abordagem da função de produção de fronteira estocástica e a metodologia proposta por Jondrow et al. (1982) para isolar os dois componentes do erro $\mathcal{E}$. E, para medir a eficiência técnica de cada firma/fazenda, adota-se o método de Timmer (1971)

\subsection{Aplicações empíricas do modelo de fronteira estocástica}

Em nível de fazenda, a primeira aplicação do modelo de função de produção de fronteira estocástica foi feita por Battese \& Corra (1977), estimando fronteiras de produção determinística e estocástica do tipo Cobb-Douglas em três estados da Austrália. Os resultados obtidos a partir da função de fronteira estocástica mostram-se bem diferentes dos obtidos na função de fronteira determinística.

Kalirajan (1981) estimou uma função de produção Cobb-Douglas de fronteira estocástica usando dados de 70 produtores de arroz da Índia. Encontrou o nível de eficiência média de 47\%. O autor investigou também as relações econômicas entre os níveis observados de eficiência e variáveis representativas de capital humano, 
tais como experiência do produtor, nivel educacional e contatos com o extensionista rural. As variáveis experiência e contatos com os serviços de extensão foram as mais importantes na determinação da eficiência técnica.

Bagi (1982a) usou uma função de produção Cobb-Douglas de fronteira estocástica para determinar se existiam diferenças significativas entre a eficiência técnica dos pequenos e grandes produtores do Tennessee, EUA. Concluiu pela inexistência de significativas diferenças entre esses grupos de produtores. Bagi (1984) utilizou o mesmo grupo de produtores para investigar a existência de diferenças significativas na eficiência técnica média de agricultores em tempo integral e agricultores em tempo parcial, não encontrando, também, diferenças significativas.

Bagi \& Huang (1983) ajustaram uma fronteira de produção translog usando os mesmos dados utilizados por Bagi $\left(1982^{a}\right)$. Os parâmetros do modelo foram estimados por mínimos quadrados corrigidos. As eficiências individuais de cada fazenda foram estimadas utilizando a estimativa de $e^{-u_{i}}$, onde $u_{i}$ foi obtido tal como descrito por Jondrow et al. (1982).

Bagi (1982 ${ }^{b}$ estimou uma fronteira de produção translog utilizando dados de agricultores da Índia. Os parâmetros foram estimados pelo método de mínimos quadrados corrigidos. A variância do termo do erro, que capta a ineficiência $\left(\boldsymbol{u}_{\boldsymbol{i}}\right)$ representou apenas uma pequena parcela da variância total. As eficiências técnicas individuais encontradas variaram entre $92 \%$ e $95 \%$. Os 
elevados índices de eficiência são consistentes com o fato da variância de $u_{i}$ ser uma pequena parcela da variância total, o que implica que a fronteira estocástica e a função média são bem similares.

Kalirajan \& Flinn (1983) calcularam a eficiência técnica de cada fazenda utilizando a metodologia desenvolvida por Jondrow et al. (1982), para um grupo de produtores de arroz das Filipinas. Utilizaram uma função de produção translog de fronteira estocástica e aplicaram o método de máxima verossimilhança para estimar os parâmetros. A eficiência técnica média foi de $50 \%$ e a individual variou de $38 \%$ a $91 \%$. Estas estimativas foram depois utilizadas para verificar se o nível de eficiência era influenciado por algumas formas de capital humano, através de um modelo de regressão linear múltipla. Experiência do agricultor e contatos com os serviços de extensão tiveram significativa influência sobre a eficiência técnica.

Huang \& Bagi (1984) utilizaram uma função de produção translog de fronteira estocástica para estimar a eficiência técnica de produtores de arroz da Índia. O nível de eficiência técnica individual variou de 75\% a 95\%, mas não houve diferença significativa entre eficiência de grandes e de pequenos produtores. O nível médio de eficiência técnica foi de 89\%.

Taylor \& Shonkwiller (1986) estimaram funções de produção de fronteira determinística e estocástica do tipo Cobb-Douglas para participantes e não participantes do programa de crédito rural, PRODEMATA, no 
Brasil. Os parâmetros foram estimados pelo método da máxima verossimilhança, com as pressuposições de que os erros tinham distribuição gama na fronteira determinística e meio normal na fronteira estocástica. A eficiência técnica foi estimada para cada unidade de produção, como sugerido por Jondrow et al. (1982). Os resultados do modelo de fronteira estocástica são diferentes do modelo de fronteira determinística. No primeiro, as estimativas para o nível médio de eficiência técnica dos participantes e não participantes do programa foram respectivamente 0.714 e 0.704 .

Kalirajan \& Shand (1986) calcularam a eficiência técnica de produtores de arroz, participantes e não participantes do Projeto de Irrigação KEMUBU na Malásia em 1980. Utilizaram uma função de produção translog de fronteira estocástica e os parâmetros do modelo foram estimados pelo método da máxima verossimilhança. A eficiência técnica individual variou de $40 \%$ a $90 \%$. Os menores níveis de eficiência são observados entre os agricultores não participantes do projeto de irrigação.

$$
\text { Kalirajan (1989) estimou a eficiência }
$$

técnica de produtores de arroz nas Filipinas em 1984-85, utilizando uma função de produção Cobb-Douglas de fronteira estocástica. Além de estimar a eficiência técnica, constatou a influência positiva de certas características individuais dos agricultores.

$$
\text { Ali \& Flinn (1989) ajustaram uma função }
$$
lucro translog de fronteira estocástica para estimar a eficiência de produtores de arroz na província de Punjab no 
Paquistão. Depois de estimarem a eficiência técnica dos agricultores, as perdas no lucro por ineficiência técnica foram utilizadas para ajustar uma regressão, em que esta variável era determinada por certas características dos produtores. Os fatores mais importantes na explicação das perdas foram nível de educação, não disponibilidade de crédito e pouco uso de irrigação e fertilizante.

$$
\text { Bravo-Ureta \& Rieger (1990) estimaram }
$$

funções de produção Cobb-Douglas de fronteiras estocástica e determinística para uma amostra de fazendas de gado de leite no nordeste dos Estados Unidos, em 1982 e 1983. Os parâmetros da fronteira determinística foram estimados por programação linear, mínimos quadrados corrigidos e máxima verossimilhança. O modelo de fronteira estocástica foi estimado pelo método de máxima verossimilhança (assumindo que $\boldsymbol{u}_{i}$ tinha uma distribuição meio-normal). As eficiências técnicas estimadas a partir dos diferentes métodos estavam altamente correlacionadas.

$$
\text { Lingard, Castillo \& Jayasuriya }
$$

estimaram a eficiência técnica de uma amostra de produtores de arroz nas filipinas, encontrando nível médio de eficiência técnica de $50 \%$ e uma relação positiva entre eficiência e experiência do fazendeiro, informação, educação e contatos com a extensão rural.

Battese \& Tessema (1992) ajustaram uma função de produção Cobb-Douglas de fronteira estocástica para estimar a eficiência técnica de agricultores da Índia. A função foi estimada pelo método de máxima verossimilhança 
e os níveis de eficiência técnica variaram no intervalo de $59 \%$ a $92 \%$

Bravo-Ureta \& Pinheiro (1997) modelaram uma função de produção Cobb-Douglas de fronteira estocástica para estimar a eficiência técnica, alocativa e econômica de pequenos agricultores na região de Dajabon, na República Dominicana. Os níveis de eficiência técnica encontrados variaram de $40 \%$ a 85\% e a eficiência técnica média foi de $70 \%$. Os autores também investigaram as relações entre níveis de eficiência técnica e tamanho da fazenda, educação e experiência. As variáveis educação e experiência tiveram impacto positivo sobre o nível de eficiência técnica.

Neff, Garcia \& Nelson (1993) estimaram a eficiência técnica de um grupo de produtores de grãos em Illinois, nos Estados Unidos. Compararam quatro especificações diferentes para estimar a eficiência técnica: dois modelos não-paramétricos e dois paramétricos (fronteira de produção determinística e estocástica). Em geral, os quatro modelos indicaram que os produtores encontram-se em elevado nível de eficiência, acima de $80 \%$. 


\section{REFERENCIAL TEÓRICO}

3.1. A função de produção fronteira e a medida de eficiência técnica

A função de produção fronteira é assumida como sendo:

$$
\begin{aligned}
& Y_{j}=f\left(X_{i j} ; B\right) e^{\varepsilon_{j}} \\
& i=1,2, \ldots \mathrm{n} \\
& j=1,2, \ldots \mathrm{m}
\end{aligned}
$$

onde $Y$, é a quantidade da produção agrícola da fazenda $j, X_{i j}$ é a quantidade do insumo $i$ utilizado pela fazenda $j$ e $B$ é um vetor de parâmetros, $\varepsilon_{j}=v_{j}-u_{j}$ é o termo de erro composto. Assume-se que os dois componentes $u_{j}$ e $v_{j}$ são independentes um do outro; onde $v_{j}$ é o erro aleatório com distribuição normal $\left(v-N\left(0, \sigma_{v}{ }^{2}\right)\right)$ e $u_{j}$ é o termo do erro que capta a ineficiência. 
Assim, o mérito deste método é a introdução de um termo de erro composto; um componente ${ }^{\prime} j$, representando erros de medida e choques exógenos fora do controle da unidade de produção e outro componente $u_{j}$ referente a medida de ineficiência.

Se o termo do erro $u_{j}=0$, a firma se localiza na fronteira de produção, obtendo a máxima produção dado o nível de insumos com que se defronta. Se " $>$, então a firma é ineficiente e produz menos devido a essa ineficiência. Se $u_{j}$ não está presente no modelo, então - modelo se transforma em uma função média, utilizada na maioria dos estudos econométricos sobre função de produção e criticado por Farrell (1957) e outros autores. Se o erro $v_{j}$ não é incluído, o modelo se transforma em fronteira determinística.

Questão importante no modelo de fronteira estocástica está relacionada às pressuposições feitas sobre a distribuição do termo de erro $u_{j}$. A maioria dos trabalhos existentes tem optado pela distribuição meio-normal, originalmente sugerida por Aigner, Lovell \& Schmidt (1977). Contudo, Stevenson (1980) propôs uma distribuição normaltruncada para $u_{j}$. O modelo por ele proposto permite que a moda da distribuição de $u_{j}$ seja diferente de zero, como originalmente sugeriram Aigner, Lovell \& Schmidt (1977). Segundo Stevenson (1980), se o termo do erro uj representa a ineficiência, então, a especificação de Aigner, Lovell \& Schmidt (1977) está baseada na hipótese implícita de que a 
função de densidade de $\boldsymbol{u}_{j}$ decresce monotonicamente para niveis crescentes de ineficiência.

Stevenson (1980) sugere que a possibilidade de moda diferente de zero para a função de densidade de $\|_{j}$ é uma pressuposição mais razoável. Neste caso, o autor propõe uma distribuição normal - truncada para representar a distribuição de $u_{j}$. Portanto, o modelo proposto por Stevenson (1980) é um caso mais geral e iguala-se ao proposto por Aigner, Lovell \& Schmidt (1977) quando $\mu=0$ (veja Apêndice 1). A escolha do modelo correto é baseada na estatística $t$ para $\mu$. Se $t$ for significativo, o modelo proposto por Stevenson (1980) é o mais adequado; caso contrário, a formulação proposta por Aigner, Lovell \& Schmidt (1977) é adequada.

No presente trabalho foram estimados os modelos propostos por Stevenson (1980) e por Aigner, Lovell \& Schmidt(1977), ou seja, considerou-se uma distribuição normal-truncada e meio-normal para $u_{j}$. A análise posterior dos resultados indicará qual deles é o mais indicado.

Para medir empiricamente a eficiência, estima-se inicialmente a função de produção de fronteira estocástica e, depois, utiliza-se a abordagem introduzida por Jondrow et al. (1982), para separar os desvios da fronteira em componentes aleatórios e de eficiência.

No caso da distribuição meio-normal para $u_{j}$, tem-se :

$$
v_{j} \sim N\left(0, \sigma_{v}^{2}\right)
$$


e, $u_{j} \sim\left|N\left(0, \sigma_{u}^{2}\right)\right|$

cujas funções de densidade são:

$$
\begin{aligned}
& f(v)=\frac{1}{\sqrt{2 \pi} \sigma_{v}} \exp \left[-\frac{1}{2}\left(\frac{v}{\sigma_{v}}\right)^{2}\right] \\
& f(u)=\frac{\sqrt{2}}{\sqrt{\pi} \sigma_{u}} \exp \left[-\frac{1}{2}\left(\frac{u}{\sigma_{u}}\right)^{2}\right]
\end{aligned}
$$

A média de $u$ é dada por:

$$
E(u)=\frac{\sqrt{2}}{\sqrt{\pi}} \sigma_{u}
$$

e a variância de $u$ é:

$$
\operatorname{Var}(u)=\left(\frac{\pi-2}{\pi}\right) \sigma_{u}^{2}
$$

A função densidade de $\varepsilon=v-u$ é obtida a partir da multiplicação das funções de densidade de $u e v$, já que são independentes um do outro. Segundo Aigner, Lovell e Schmidt (1977), a função de densidade de $\varepsilon$ é:

$$
f(\varepsilon)=\frac{2}{\sigma} f\left(\frac{\varepsilon}{\sigma}\right)\left[1-F\left(\frac{\varepsilon \lambda}{\sigma}\right)\right]
$$

Onde $F$ é a Eunção de distribuição normal padrão, $f$ é a função de densidade normal padrão e $\sigma^{2}=\sigma_{v}^{2}+\sigma_{u}^{2}$ e $\lambda=\sigma_{u} / \sigma_{1}$ 
Neste caso, o logaritmo da função de máxima verossimilhança segundo Aigner, Lovell \& Schmidt (1977), Schmidt \& Lovell (1979) e Greene (1990), é:

$$
\ln L=n \ln \left(\frac{2}{\pi}\right)^{\frac{1}{2}}-\frac{n}{2} \ln \sigma^{2}+\sum_{j=1}^{n} \ln \left[1-F\left(\frac{\varepsilon_{j} \lambda}{\sigma}\right)\right]-\frac{1}{2 \sigma^{2}} \sum_{j=1}^{n} \varepsilon_{j}^{2}
$$

Jondrow et al. (1982) demonstraram que as pressuposições feitas sobre as distribuições estatísticas de $v_{j}$ e $u_{j}$, mencionadas acima, possibilitam o cálculo do significado condicional de $u_{i}$ dado $\varepsilon_{j}$, como:

$$
E\left(u_{j} \mid \varepsilon_{j}\right)=\sigma_{*}\left[\frac{f\left(\varepsilon_{j} \lambda / \sigma\right)}{1-F\left(\varepsilon_{j} \lambda / \sigma\right)}-\frac{\varepsilon_{j} \lambda}{\sigma}\right]
$$

onde $f$ e $F$ são, respectivamente, as funções de densidade normal padrão e de distribuição normal padrão, $\sigma_{*}^{2}=\sigma_{u}^{2} \sigma_{v}^{2} / \sigma^{2}, \quad \sigma^{2}=\sigma_{u}^{2}+\sigma_{v}^{2}$ e $\lambda=\sigma_{u} / \sigma_{v}$

Assim, a equação (16) fornece estimativas de $u_{j}$ e $v_{j}$ depois da substituição de $\varepsilon, \sigma, \lambda$ por suas estimativas, obtidas a partir da maximização da função de máxima verossimilhança, sendo expressa pela equação (15).

No caso de uma distribuição normal-truncada

para $u_{j}$ :

$$
\begin{aligned}
& v_{j} \sim N\left(0, \sigma_{y}^{2}\right) \\
& e_{1}
\end{aligned}
$$




$$
u_{j} \sim N\left(\mu, \sigma_{u}^{2}\right)
$$

$$
f(v)=\frac{1}{\sqrt{2 \pi} \sigma_{v}} \exp \left[-\frac{1}{2}\left(\frac{v}{\sigma_{v}}\right)^{2}\right]
$$

$$
f(u)=\frac{1}{\left[1-F\left(\mu / \sigma_{u}\right)\right] \sqrt{2 \pi} \sigma_{u}} \exp \left[\frac{-1}{2}\left(\frac{u-\mu}{\sigma_{u}}\right)^{2}\right]
$$

A média de $u$ é dada por:

$$
E(u)=\frac{\mu}{2}\left[1-F\left(\frac{\mu}{\sigma_{u}}\right)\right]^{-1}+\frac{\sigma_{u}}{\sqrt{2 \pi}}\left[1-F\left(\frac{\mu}{\sigma_{u}}\right)\right]^{-1} \exp \left[\frac{-1}{2}\left(\frac{\mu}{\sigma_{u}}\right)^{2}\right]
$$

E a variância de u:

$$
\operatorname{Var}(u)=\mu^{2} \frac{a}{2}\left(1-\frac{a}{2}\right)+\sigma_{u}^{2} \frac{a}{2}\left(\frac{\pi-a}{\pi}\right)
$$

onde

$$
a=\left[1-F\left(\mu / \sigma_{u}\right)\right]^{-1}
$$

A função de densidade de $\varepsilon$, segundo Stevenson (1980), é:

$$
f(\varepsilon)=\frac{1}{\sigma} f\left(\frac{\varepsilon-\mu}{\sigma}\right)\left[1-F\left(\frac{\mu}{\sigma \lambda}+\frac{\varepsilon \lambda}{\sigma}\right)\right]\left[1-F\left(\frac{\mu}{\sigma_{u}}\right)\right]^{-1}
$$


onde $f$ e $F$ são, respectivamente, as funções de densidade normal padrão e de distribuição normal padrão, $\sigma^{2}=\sigma_{u}^{2}+\sigma_{v}^{2}$ e $\lambda=\sigma_{u} / \sigma_{v}$

Neste caso, Stevenson (1980) demonstra que o logaritmo da função de máxima verossimilhança é:

$$
\begin{aligned}
& \ln L=n \ln \left(\frac{2}{\pi}\right)^{\frac{1}{2}}-\frac{n}{2} \ln \sigma^{2}-\frac{1}{2 \sigma^{2}} \sum_{j=1}^{n}\left(\varepsilon_{j}-\mu\right)^{2}+ \\
& +\sum_{j=1}^{n} \ln \left[1-F\left(\frac{\mu}{\lambda \sigma}+\frac{\varepsilon_{j} \lambda}{\sigma}\right)\right]-n \ln \left\{1-F\left[\frac{\mu}{\sigma}\left(\lambda^{-2}+1\right)^{\frac{1}{2}}\right]\right\}
\end{aligned}
$$

Segundo Greene (1991), para a obtenção das estimativas de $u_{j}$ é utilizada a fórmula abaixo, que é uma generalização da fórmula 16, descrita anteriormente, para o caso em que $\mu=0$ (veja Apêndice 1 ).

$$
E\left(u_{j} / \varepsilon_{j}\right)=\sigma *\left[\frac{f\left(\frac{\varepsilon_{j} \lambda}{\sigma}+\frac{\mu}{\lambda \sigma}\right)}{1-F\left(\frac{\varepsilon_{j} \lambda}{\sigma}+\frac{\mu}{\sigma \lambda}\right)}-\left(\frac{\varepsilon_{j} \lambda}{\sigma}+\frac{\mu}{\sigma \lambda}\right)\right]
$$

Uma vez obtidas as estimativas de $\|_{j}$ para cada uma das especificações (meio-normal e normaltruncada), é possível calcular a medida de eficiência técnica para cada fazenda e também a medida de eficiência técnica média. 
A medida de eficiência técnica de cada fazenda é assim obtida:

$$
T E_{j}=Y_{j} / Y_{j}^{*}
$$

Onde $Y_{j}^{*}$ é o nível de produção na fronteira.

Portanto,

$$
T E_{j}=f\left(X_{i} ; \beta\right) e^{v_{j}-u_{j}} / f\left(X_{i} ; \beta\right) e^{u^{\prime}}
$$

Ou seja,

$$
T E_{j}=e^{-u_{j}}
$$

Conclui-se que a eficiência técnica máxima é igual a 1, caso em que a firma está produzindo na fronteira e $Y_{j}^{*}=Y_{j}$

A eficiência técnica na fazenda $j$ tem sido estimada em diversos estudos empíricos a partir da diferença $1-E\left(u_{j} / \varepsilon_{j}\right)$. Battesi \& Coelli (1988), no entanto, advertem que quando a função é expressa na forma logarítmica, tal como no presente trabalho, a medida correta da eficiência técnica é $e^{-\| \text {J }}$.

A eficiência técnica média (TE), como estimada por Battesi \& Coelli, (1988) é:

i) se u tem distribuição meio-normal: 
$T E=2\left[1-F\left(\sigma_{u}\right)\right] \exp \left(\frac{1}{2} \sigma_{u}{ }^{2}\right) ; e$

ii) se "l tem uma distribuição normaltruncada:

$$
T E=\left\{\frac{1-F\left[\sigma_{u}-\left(\frac{\mu}{\sigma_{u}}\right)\right]}{1-F\left(\frac{\mu}{\sigma_{u}}\right)}\right\} \exp \left(-\mu+\frac{1}{2} \sigma_{u}^{2}\right)
$$




\section{METODOLOGIA}

\subsection{Modelo empírico da função fronteira}

A forma funcional Cobb-Douglas é utilizada para estimar fronteira de produção estocástica. Vale ressaltar que esta forma funcional tem sido freqüentemente usada em análises de eficiência no setor agricola ${ }^{3}$. Em um dos poucos estudos que examinam o impacto de especificaçoses distintas sobre a estimação de eficiência técnica, Kopp \& Smith (1980) encontraram um impacto muito pequeno da forma funcional escolhida sobre a eficiência estimada ${ }^{4}$.

A função de produção Cobb-Douglas apresenta algumas limitações, como por exemplo, o fato da elasticidade substituição entre fatores ser constante $e$ igual a unidade. Em compensação, apresenta algumas vantagens que facilitam a estimação econométrica, já que é linear nos parâmetros, em sua forma logarítmica. Além

\footnotetext{
Veja Battese (1992) e Bravo-Ureta \& Pinheiro (1993) para uma revisão da literatura empírica disponivel.

† Mais recentemente, Good et al. (1993) também argumentaram que a escolha da forma funcional não tem impacto significativo sobre o nivel de eficiência.
} 
disso, as elasticidades de produça são dadas pelos coeficientes da regressão e podem ser diretamente comparados entre si, visto serem independentes das quantidades de produto e de fatores. E, como a Eunção CobbDouglas é uma função homogênea, a natureza dos rendimentos à escala é determinada diretamente pela soma dos coeficientes da regressão.

o uso do modelo de uma única equação é justificado ao se assumir que os agricultores maximizam os lucros esperados, procedimento adotado comumente em estudos deste tipo (Zeliner, Kmenta \& Drèze, 1965; Kopp \& Smith, 1980; Caves \& Barton, 1991) ${ }^{5}$.

o modelo a ser estimado é:

$Y_{j}=\beta_{0} T^{\beta_{1}} L^{\beta_{2}} M^{\beta_{3}} e^{\varepsilon_{j}}$

Que na sua forma logarítmica é:

$\ln Y_{1}=\ln \beta_{0}+\beta_{1} \ln T+\beta_{2} \ln L+\beta_{i} \ln M+\varepsilon_{i}$

Onde,

$Y_{j}=$ Valor da produção agrícola da fazenda $j$

\footnotetext{
"Kumbhakar \& Hjalmarsson (1993. pg 426) argumentam da seguinte forma : "Assumimos que o objetivo da firma é a maximização de lucros. Além disso, no presente estudo consideramos os insumos como exógenos. Pode-se justificar esta pressuposição em termos de um processo de decisão onde a escolha dos insumos é feita antes da decisão de produção. Neste caso, a maximização dos lucros, dados os insumos (exógenos) e o preço do produto, é equivalente à maximização da produção. Este arģumento está de acordo com a definição da função de produção encontrada nos livros textos. Neste sentido. sua estimação é consistente com a hipótese de maximização dos lucros."
} 


$$
\begin{aligned}
T= & \text { Área explorada (em hectares); } \\
I= & \text { Mão-de-obra (em dias-homem); } \\
M= & \text { Despesas com sementes, fertilizantes, } \\
& \text { defensivos e corretivos e reparos em } \\
& \text { máquinas, equipamentos e benfeitorias; } \\
& e,
\end{aligned}
$$

$\varepsilon_{j}=$ termo de erro composto, $v_{j}-u_{j}$

\subsection{Definição das variáveis da função fronteira}

- Valor total da produção (Y) - valor total da produção no ano agrícola 1989/90, expresso em cruzeiros de julho de 1990. Inclui o valor dos produtos agrícolas e pecuários vendidos e consumidos.

- Área explorada (T) - definida pelo número de hectares utilizados, inclusive por arrendamento, em culturas permanentes e/ou temporárias e em pastagens.

- Mão-de-obra (L) - é a quantidade de dias-homem utilizada no processo produtivo do ano agrícola $1989 / 90$.

- Gastos (M) - inclui gastos com defensivos, corretivos, fertilizantes, sementes, reparos com máquinas, equipamentos e benfeitorias, expressos em cruzeiros de julho de 1990; 
As variáveis explanatórias especificadas neste modelo têm sido comumente utilizadas na estimação de fronteiras de produção agrícola (Taylor, Drummond \& Gomes, 1986; Taylor \& Shonkwiller, 1986; Belbase \& Grabowiski, 1985; Neff, Garcia \& Nelson, 1993; Bravo-Ureta \& Evenson, 1994; e, Bravo-Ureta \& Pinheiro, 1997).

Uma vez estimada a função de produção cobbDouglas de fronteira estocástica, o passo seguinte é aplicar a metodologia de Jondrow et al. (1982) para decompor $\varepsilon_{j}$ em $v_{j} e u_{j}$. A partir da obtenção da estimativa de $u_{j}$, pode-se calcular a eficiência técnica de cada fazenda.

Como já mencionado, a eficiência técnica de cada fazenda é dada por:

$$
T E_{j}=e^{-u}
$$

\subsection{Modelo TOBIT}

Para objetivos de politicas públicas, é útil identificar os fatores determinantes de $T E_{j}$, pela estimativa de relações econométricas entre os níveis de eficiência técnica de cada fazenda e algumas variáveis representativas do capital humano.

Segundo Bravo-Ureta \& Pinheiro (1997), 0 modelo Tobit é adequado para estimar a influência das variáveis representativas do capital humano sobre os níveis observados de eficiência. 
De fato, os níveis de eficiência técnica somente assumem valores no intervalo de 0 a 1 lou de $0 \%$ a 100\%). O nível de eficiência estimado representa a eficiência de cada produtor e não a percentagem de produtores eficientes. A variável dependente leficiência técnica) não é dicotômica, ela é censorada, ou seja, varia em intervalo determinado, isto é, não é menor do que zero, nem maior do que 1 .

Assim sendo, é utilizado o modelo Tobit, especialmente indicado para casos em que a variável dependente é observada apenas em um dado intervalo de valores.

Hussain et al. (1994) mostram, de forma objetiva, a adequação do uso do modelo Tobit. Os autores utilizam os modelos Logit e Tobit para verificar o impacto de variáveis representativas de capital humano na adoção de tecnologia. No primeiro modelo, a variável dependente (adoção de tecnologia) é binária (assume valor zero se a tecnologia não é adotada e valor 1, se adotada). No segundo modelo, a variável dependente é um índice (que varia de zero até certo nível).

Isto posto, pode-se admitir que o modelo Tobit é adequado para o presente estudo tendo em vista que:

i) ocorre uma truncagem na variável dependente $\left(y_{i}=\right.$ eficiência técnica), uma vez que é apenas observada no intervalo $100 \% \geq y_{i} \geq 0 \%$;

ii) as variáveis independentes $\left(x_{i}\right)$ são observadas em todas as unidades da amostra. 
Uma forma simplificada do modelo de TOBIT é a seguinte:

$$
\begin{array}{ll}
y_{j}{ }^{*}=x_{j}(\beta)+u_{j}, & u_{j} \sim \operatorname{NID}\left(0, \sigma^{2}\right) \\
y_{j}=y_{j}^{*} ; \quad \text { se } \quad y_{j}>0 & \text { e, } y_{j}^{*}=0 \text { se; } y_{j} \leq 0
\end{array}
$$

Neste caso $y_{j}^{*}$ é uma variável latente e observada somente quando for positiva. Quando esta variável latente é negativa tem-se o valor zero como observação. Ou seja, o limite inferior é zero.

Este modelo pode ser modificado de tal forma que o truncamento ocorra em outro valor que não o zero ou que ocorra tanto no limite inferior, quanto no superior.

Quando o truncamento ocorre tanto no limite inferior quanto no superior (caso do presente estudo) temse o modelo two-limit tobit, que pode ser descrito da seguinte forma, segundo Davidson e Mackinnon (1993):

$$
\begin{array}{lll}
y_{j}{ }^{*}=x_{j}(\beta)+u_{j} & & u_{j} \sim N\left(0, \sigma^{2}\right) \\
y_{j}=y_{j}^{*} & \text { se } \quad y_{j}^{l} \leq y_{j} \leq y_{j}{ }^{\prime \prime} \\
y_{j}^{*}=y_{j}^{l} & \text { se } \quad y_{j}<y_{j}^{l} \\
y_{j}^{*}=y_{j}^{\prime \prime} & & \text { se } \quad y_{j}>y_{j}^{\prime \prime}
\end{array}
$$


No modelo de Tobit, como mostrado por Greene (1997), Judge et al. (1988) e Maddala (1988), o procedimento de mínimos quadrados ordinários não é adequado para a estimação dos parâmetros, tendo em vista que as estimativas de MQO são viesadas e inconsistentes. Em função disso, utiliza-se o método de máxima verossimilhança.

No caso do modelo two-Iimit Tobit, logaritmo da função de máxima verossimilhança é, segundo Davidson \& Mackinnon (1993, pag 540), o seguinte:

$$
\begin{aligned}
& \ln L=\sum_{y^{\prime} \leq y^{\prime \prime} \leq y^{\prime \prime}} \ln \left\{\frac{1}{\sigma} f\left[\frac{1}{\sigma}(y-X \beta)\right]\right\}+\sum_{y^{\prime}<y^{\prime}} \ln \left\{F\left[\frac{1}{\sigma}\left(y^{\prime}-X \beta\right)\right]\right\}+ \\
& +\sum_{I^{\prime}>y^{\prime \prime}} \ln \left\{F\left[\frac{-1}{\sigma}\left(y^{\prime \prime}-X B\right)\right]\right\}
\end{aligned}
$$

Onde $f$ e $F$ são, respectivamente, as funções de densidade e de distribuição normal padrão.

A maximização da função acima oferece as estimativas dos parâmetros.

Com base nas considerações anteriores, para testar a influência de variáveis representativas de capital humano sobre o nível de eficiência técnica, foram estimados os seguintes modelos empíricos:

$$
\begin{aligned}
& T E_{j}=\beta_{0}+\beta_{1} E s c+\beta_{2} E x p+\beta_{3} E x t+\beta_{4} \text { Epriv }+\beta_{5} \text { Radio }+\xi \\
& T E_{j}=\alpha_{0}+\alpha_{1} E s c_{1}+\alpha_{2} E x p+\alpha_{3} E x t+\alpha_{4} \text { Epriv }+\alpha_{5} \text { Radio }+\mu
\end{aligned}
$$




\subsection{Definição das variáveis do modelo TOBIT}

As variáveis Esc, Exp e Ext, Epriv e Rádio representam, respectivamente, a escolaridade do responsável pela fazenda, experiência, contatos com os serviços de extensão rural pública, contatos com extensão privada e acesso a informação técnica através de programas de rádio. Nas equações 37 e 38, a variável dependente é o índice de eficiência técnica. As variáveis independentes são binárias. Assumem valor 1, quando iguais ou superiores à média da amostra e valox zero, quando inferiores ${ }^{6}$. No caso da variável educação, são testadas duas especificações.

As variáveis do modelo Tobit são assim definidas:

- Eficiência Técnica $\left(T E_{i}\right)$ - medida na forma de índice, em percentagem;

- Escolaridade (ESC) - anos de estudo formal do responsável pela propriedade agrícola. Assume valor 1 se número de anos de estudo formal for igual ou superior a 8 (escolaridade média da amostra) e valor zero, se inferior;

- Escolaridade (Escil - medida em anos de estudo formal do responsável pela propriedade agrícola. Assume valor 1 , se o número de anos de estudo formal for igual ou superior a 4 e valor zero, se inferior;

- Experiência (Exp) - medida diretamente pelo número de anos que o responsável pela propriedade

\footnotetext{
Bravo-Lreta \& Pinheiro (1997) utilizaram uma especificação empírica bem semelhante a adotada no presente estudo.
} 
agrícola se dedica à atividade. Assume valor 1, se superior a 10 anos e valor zero, se inferior;

- Extensão Pública (Ext) - número de contatos que o responsável pela propriedade agrícola teve com o serviço de extensão pública no ano agrícola. Assume valor 1, se o número de contatos for igual ou superior a 14 e zero, se inferior;

- Extensão Privada (Epriv) - medida da mesma forma que a variável extensão pública. Assume valor 1, se o número de contatos for maior do que 18, e valor zero, se inferior;

- Rádio - Assume valor 1 se o responsável pela fazenda teve acesso a informação técnica pelo rádio e zero, se não.

A maioria dos trabalhos utiliza especificações semelhantes às mencionadas acima para investigar possíveis variáveis que possam explicar as diferenças de eficiência. Os trabalhos de Bravo-Ureta \& Evenson (1994), Huang \& Bagi (1984), Kalirajan (1991), Ray (1985) e Squires \& Tabor (1991) são alguns exemplos.

No caso da educação formal escolheu-se a especificação da variável dummy Esc em função da evidência empírica documentada na literatura de que nível educacional inferior a quatro anos não tem efeito sobre a produção e a produtividade agrícola. Esta foi uma das grandes conclusões do trabalho de Loockeed, Jaminson \& Lau (1980), sistematicamente citada para justificar a inexistência de impacto dessa variável sobre a produção/eficiência. Essa argumentação foi também utilizada nos trabalhos de shapiro 
(1983), Moock (1985), Lipton (1985), Phillipps \& Marble (1986) e Azhar (1991).

A variável experiência é muito utilizada nos modelos two-step, e tem respaldo teórico na literatura do learning by doing, defendida principalmente por Arrow (1962) e Rosen (1972). Os agricultores com mais experiência teriam maior conhecimento do processo produtivo e por isso seriam mais eficientes.

A variável extensão, como explicitada nos modelos two-step, tem efeito positivo sobre a produção agrícola e sobre as taxas de adoção e difusão de tecnologia.

Os serviços de extensão (pública e privada) não têm apenas o objetivo de levar ao conhecimento dos produtores novas descobertas tecnológicas, mas também de orientá-los a produzir de modo mais eficiente. O trabalho de Birkhaeuser, Evenson \& Feder (1991) faz uma detalhada revisão de literatura do impacto econômico dos serviços de extensão sobre o nível de produção. E o trabalho de Feder, Just \& Zilberman (1985) analisa o impacto da extensão sobre a adoção de inovações agrícolas nos países em desenvolvimento. No caso da América Latina, deve-se registrar a excelente contribuição de Schuh e Brandão (1990).

Finalmente, a variável rádio foi usada com o objetivo de se verificar a influência de fontes alternativas de informação sobre a eficiência técnica. Hussain et al. (1994) utilizou esta variável para estimar seu impacto sobre a adoção de tecnologias no Punjab, Paquistão. 


\subsection{Dados e Regiões}

Neste estudo, os dados são de fonte primária, obtidos a partir de uma amostra de 330 propriedades, situadas em 11 regiões agrícolas do Brasil (Araújo et al., 1990). O projeto Mobilização de Poupança, Formação de Capital e Mercados Financeiros na Agricultura Brasileira, financiado pelo Banco Mundial, objetivou fazer um amplo levantamento de campo através de entrevistas com agricultores, gerentes de bancos e cooperativas, técnicos e empresários agro-industriais. Foram escolhidas, intencionalmente, regiões que representassem a agricultura de subsistência (baixa renda) e regiões representativas da agricultura comercial (capital intensiva e altamente tecnificada).

Os dados são apropriados para o presente estudo já que as informações foram coletados diretamente nas unidades produtivas e submetidas a um rigoroso processo de avaliação, inclusive durante a fase de levantamento.

$$
\text { Dentre as regiões visitadas, foram }
$$

selecionadas para o presente estudo as de agricultura moderna/comercial. A escolha do segmento moderno da agricultura brasileira é, como demonstrado nos capítulos iniciais, coerente com o objetivo central da pesquisa.

As regiões escolhidas e os respectivos números de entrevistas em cada uma delas são: i) Rio Verde, GO (21 entrevistas); ii) Rondonópolis, MT (26 entrevistas); iii) São Gabriel d'Oeste, MS (25 entrevistas); iv) Carazinho, RS (36 entrevistas). Assim, tem-se o total de 108 observações do ano agrícola 1989/90. Nessas regiões, as 
fazendas são produtoras de grãos, tendo na cultura da soja sua principal atividade.

O município de Rio Verde, na microrregião da Serra do Caiapó do Estado de Goiás, caracteriza-se por uma agricultura comercial, de alta tecnologia e praticada em grande escala. Muitos dos agricultores desta região são provenientes de estados do sul do país e, por excelência, produtores de soja, no período em análise.

O município de Rondonópolis, na microrregião de mesmo nome, do Estado do Mato Grosso, é grande produtor de soja e apresenta uma agricultura intensiva, em larga escala, e reduzido uso de mão-de-obra.

O município de São Gabriel d'Oeste do Estado do Mato Grosso do sul situa-se na microrregião de Alto Taquari e também representa uma agricultura capital intensiva, explorada em média escala, e embasada praticamente na cultura da soja.

Finalmente, o município de Carazinho, localizado na microrregião de Passo Fundo do Rio Grande do Sul, possui um setor agrícola tecnificado e índice de mecanização relativamente alto. Suas unidades de produção estão voltadas principalmente para a produção de grãos, em especial, soja, milho e trigo.

A Tabela 1 apresenta estatísticas que caracterizam os valores médios da área explorada e da quantidade de mão-de-obra por região. 
Tabela 1. Média da área explorada e utilização da mão-de-obra nas regiões analisadas, $1989 / 90$

\begin{tabular}{|c|c|c|}
\hline Região & $\begin{array}{c}\text { Área Explorada } \\
\text { (ha) }\end{array}$ & $\begin{array}{c}\text { Mão-de-obra } \\
(e m E H)^{(a)}\end{array}$ \\
\hline Rio Verde & 481,00 & 5,80 \\
\hline Rondonópolis & 412,50 & 3,90 \\
\hline São Gabriel d'Oeste & 254,400 & 3,00 \\
\hline Carazinho & 174,40 & 4,40 \\
\hline Amostra & 307,80 & 4,20 \\
\hline
\end{tabular}

A área média expiorada apresenta uma certa variação entre as regiões, mas em todas elas esse fator é utilizado em média e larga escalas. O número médio de equivalentes-homem utilizado demostra que o fator trabalho não é muito utilizado no processo produtivo.

o padrão tecnológico das fazendas da amostra, identificado a partir de práticas agrícolas selecionadas, é homogêneo, conforme pode ser visto na Tabela 2. As práticas agrícolas especificadas são características de agricultores modernos. 
Tabela 2. Número de agricultores que utilizam práticas agrícolas selecionadas, 1989/90.(a)

\begin{tabular}{lccccc}
\hline Região & $\begin{array}{c}\text { Análise } \\
\text { de } \\
\text { Solos }\end{array}$ & $\begin{array}{c}\text { Aplicaça } \\
\text { de } \\
\text { Calcáreo }\end{array}$ & $\begin{array}{c}\text { Uso de } \\
\text { Sementes } \\
\text { Melhoradas }\end{array}$ & $\begin{array}{c}\text { Aplicação } \\
\text { de } \\
\text { Herbicidas }\end{array}$ & $\begin{array}{c}\text { Conservacão } \\
\text { dos Solos }\end{array}$ \\
\hline Rio Verde & 19 & 18 & 20 & 13 & 20 \\
& $(90,4)$ & $(85,7)$ & $(95,2)$ & $(61,9)$ & $(95,2)$ \\
Rondonópolis & 21 & 18 & 26 & 23 & 20 \\
& $(80,7)$ & $(69,2)$ & $(100)$ & $(88,4)$ & $(76,9)$ \\
São Gabriel & 25 & 25 & 25 & 25 & 25 \\
d'Oeste & $(100)$ & $(100)$ & $(100)$ & $(100)$ & $(100)$ \\
Carazinho & 31 & 33 & 30 & 30 & 27 \\
& $(86,1)$ & $(91,6)$ & $(83,6)$ & $(83,6)$ & $(75,0)$ \\
\hline
\end{tabular}

Fonte: Araújo et al. (1990).

Nota: (a) Os números entre parênteses são as percentagens correspondentes.

Os agricultores amostrados em Rio Verde utilizam, em sua grande maioria, sementes melhoradas e técnicas de conservação e análise dos solos. O percentual de produtores que faz aplicação de calcáreo é um pouco menor, mas ainda assim expressivo. A técnica que aparece com menor freqüência é a aplicação de herbicidas.

Em Rondonópolis, a situação é similar. Entretanto, nesta região, a prática menos utilizada é a aplicação de calcáreo. Vale dizer que todos os agricultores amostrados nesta região utilizam sementes melhoradas.

Em São Gabriel d'Oeste todas as práticas agrícolas constantes da tabela 2 são utilizadas pela totalidade dos agricultores amostrados.

O município de Carazinho também apresenta uma dinâmica que não difere muito dos demais. A prática mais utilizada é a aplicação de calcáreo e a menos utilizada é a conservação dos solos. 
Como os agricultores das quatro regiões selecionadas apresentam características de produção e uso de fatores similares, é possível considerá-ios representativos da agricultura comercial/moderna do Brasil. 


\section{ANÁLISE DOS RESULTADOS}

Foram estimados dois modelos de fronteira de produção estocástica', um sob a pressuposição de que o termo do erro que capta a ineficiência $u_{i}$ tem distribuição normal-truncada e outro, sob a pressuposição de que a distribuição seria meio-normal. Os resultados do primeiro modelo indicam que a pressuposição normal-truncada não é adequada, já que o teste $t$ para $\circ$ parâmetro $\mu$ não foi significativo, ou seja, não se pode rejeitar a hipótese de $\mu$ ser estatisticamente igual a zero. Os resultados deste modelo são apresentados no Apêndice 2 .

Desta forma, a análise dos resultados será restrita ao segundo modelo, qual seja, o de distribuição meio-normal para o termo do erro.

Inicialmente, para efeito de comparação, foi estimada uma função de produção Cobb-Douglas pelo método de mínimos quadrados ordinários, isto é, estimou-se uma função média. Em seguida, estimou-se a fronteira de produção estocástica Cobb-Douglas, a partir do método de máxima verossimilhança. os resultados estão sumarizados na Tabela 3.

\footnotetext{
${ }^{7}$ Foi utilizado o prøgrama estatístico LIMDEP para estimar a fronteira de produção estocástica.
} 
Tabela 3- Estimativa dos parâmetros da função de Produção Cobb-Douglas e da Fronteira de Produção Estocástica Cobb-Douglas para Amostra de Agricultores Comerciais, $1989 / 90$.

\begin{tabular}{|c|c|c|}
\hline Variáveis & $\begin{array}{l}\text { Função } \\
\text { Média } \\
\end{array}$ & $\begin{array}{c}\text { Função Fronteira } \\
\text { Estocástica }\end{array}$ \\
\hline Intercepto & $\begin{array}{l}7.73880 * \\
(12.013)\end{array}$ & $\begin{array}{l}7.81800^{\star} \\
(12.861)\end{array}$ \\
\hline Terra & $\begin{array}{r}0.49547^{*} \\
(6.897)\end{array}$ & $\begin{array}{r}0.48409 * \\
(7.394)\end{array}$ \\
\hline Trabalho & $\begin{array}{l}0.12015 * \star \\
(2.202)\end{array}$ & $\begin{array}{r}0.15310^{\star} \\
(2.587)\end{array}$ \\
\hline $\begin{array}{l}\text { Gastos Insumos } \\
\text { Modernos }\end{array}$ & $\begin{array}{r}0.27048 * \\
(4.617) \\
\end{array}$ & $\begin{array}{r}0.27695^{\star} \\
(5.387) \\
\end{array}$ \\
\hline Teste $\mathrm{F}$ & $302.23 *$ & --- \\
\hline $\begin{array}{l}\text { Quasi function } \\
\text { Coefficient }\left(\sum \beta_{i}\right)\end{array}$ & 0.886 & 0.914 \\
\hline $\begin{array}{l}\text { Teste } F(R C E) \\
\text { Teste Wald (RCE) }\end{array}$ & $5.76 * \star$ & $3.43^{* x}$ \\
\hline $\mathrm{R}^{2}$ Ajustado & $0.89 \star$ & - \\
\hline$\lambda$ & & $\begin{array}{l}1.7943 * \star \\
(2.236)\end{array}$ \\
\hline$\sigma$ & & $\begin{array}{l}0.4886 * \\
(5.350)\end{array}$ \\
\hline$\sigma_{\mathrm{v}}^{2}$ & & 0.05658 \\
\hline$\sigma_{u}^{2}$ & & 0.18214 \\
\hline $\begin{array}{l}\text { LFMV } \\
\mathrm{n}=108\end{array}$ & & -38.73136 \\
\hline $\begin{aligned} \text { Fonte: } & \text { Dados da pesquis } \\
\text { Nota: } & * \text { significativo } \\
& * * \text { significativo } \\
& \star * \star \text { significativo } \\
& \text { LFMv Logaritmo } \\
& \text { Os números entr } \\
& \text { estatística "t". }\end{aligned}$ & $\begin{array}{l}\text { el de } 1 \% \\
\text { vel de } 5 \% \\
\text { vel de } 10 \% \\
\text { ão de Máxima } \\
\text { tênteses ref }\end{array}$ & $\begin{array}{l}\text { ssimilhança. } \\
\text { e aos valores }\end{array}$ \\
\hline
\end{tabular}


Os resultados mostram um bom ajuste da função de produção Cobb-Douglas. Os parâmetros estimados são significativos ao nível de 1\%, com exceção do fator trabalho, significativo ao nível de 5\%. O $R^{2}$ ajustado é elevado, igual a $89 \%$ e o teste $F$ significativo ao nível de 1\%. As variáveis utilizadas explicam, portanto, aproximadamente $90 \%$ da produção.

Como a função de produção Cobb-Douglas é estimada em sua forma logarítmica, os parâmetros expressam as elasticidades da produção com relação aos insumos. Os resultados encontrados são bastante coerentes, tanto no que se refere aos sinais esperados quanto à importância de cada insumo na explicação da produção. A terra é o fator que tem maior impacto sobre a produção, o que era de se esperar já que a amostra utilizada refere-se a produtores que utilizam esse fator em larga escala. O fator que tem menor impacto é a mão-de-obra, o que também era esperado, pois, nas regiões estudadas o grau de mecanização é elevado. A influência da variável gastos com insumos modernos é mais do que o dobro da variável mão-de-obra.

Como salientado anteriormente, a soma dos coeficientes da função Cobb-Douglas é uma estimativa dos retornos à escala. Se a soma dos coeficientes for menor do que um, os produtores estariam produzindo com retornos decrescentes à escala; se a soma for igual a um, com retornos constantes à escala e se maior do que a unidade, com retornos crescentes à escala. No caso da função média a soma dos coeficientes é igual a 0.886. Para se testar formalmente a hipótese de retornos constantes à escala, foi feita a estimação por mínimos Quadrados Restritos. O valor do teste $F$ para o modelo restrito foi de 5,76, portanto, 
rejeitado ao nível de 5\% de significância. Isto significa que os produtores analisados estão produzindo com retornos decrescentes à escala. Um aumento de $10 \% \mathrm{em}$ todos os insumos utilizados, ocasiona um aumento de $8,86 \%$ na produção.

No caso da função fronteira, a soma dos coeficientes estimados é igual a 0.914. Para se testar formalmente a hipótese de retornos constantes à escala, foi feito o teste de wald. A estatística de wald foi 3,43 e rejeitou-se a hipótese de retornos constantes à escala somente ao nível de 10\%.

No que se refere aos resultados da fronteira de produção, verifica-se que as estimativas dos parâmetros são muito semelhantes às encontradas no modelo de função média, com exceção do termo constante, que é maior no caso da fronteira do parâmetro da variável mão-de-obra, que também é maior. Este fato indica que a função fronteira não representa um deslocamento completamente neutro em relação à função média.

No caso da estimação da função fronteira estocástica, $\quad$ parâmetro $\lambda=\sigma_{u} / \sigma_{\text {, }}$ é especialmente importante. No modelo estimado, $\lambda=1.7949$, estatisticamente significativo, o que implica que o termo do erro $\|_{j}$ domina $v_{j}$, ou seja, a diferença entre a produção observada e a produção fronteira é explicada, principalmente, por ineficiência técnica. O parâmetro $\gamma=\lambda^{2} /\left(1+\lambda^{2}\right)=\sigma_{u}{ }^{2} / \sigma^{2}$ mede o efeito da ineficiência na variação da produção observada (Bravo-Ureta \& Pinheiro, 1997). No presente estudo $\gamma$ é igual a 0.76, o que significa que $76 \%$ da variação na produção são atribuídos à ineficiência técnica. 
Uma vez estimada a função de produção de fronteira estocástica e obtida a estimativa de $u_{j}$, a partir da metodologia de Jondrow et al. (1982), é possível calcular a medida de eficiência técnica de cada fazenda e também a eficiência técnica média. No apêndice 3, são apresentadas as estimativas de $u_{j}$ e as respectivas medidas de eficiência técnica de cada fazenda.

A Tabela 4 apresenta a distribuição de Ereqüência da estimativa de eficiência técnica para o grupo de agricultores em estudo. Veja também a Figura 4.

Tabela 4. Distribuição de Ereqüência da eficiência técnica.

\begin{tabular}{lr}
\hline $\begin{array}{c}\text { Nível de } \\
\text { Eficiência (\%) }\end{array}$ & $\begin{array}{r}\text { Número de } \\
\text { Produtores }\end{array}$ \\
\hline$>90$ & 1 \\
$>85<90$ & 14 \\
$>80<85$ & 21 \\
$>75<80$ & 20 \\
$>70<75$ & 15 \\
$>65<70$ & 9 \\
$>60<65$ & 8 \\
$>55<60$ & 6 \\
$>50<55$ & 6 \\
$>45<50$ & 3 \\
$>40<45$ & 5 \\
Total & 108 \\
Média & $73.08 \%$ \\
Máximo & $93.09 \%$ \\
Mínimo & $41.47 \%$ \\
\hline Fonte: &
\end{tabular}

Fonte: Dados dá Pesquisa 
Figura 4. Distribuição de Freqüência da Eficiência Técnica

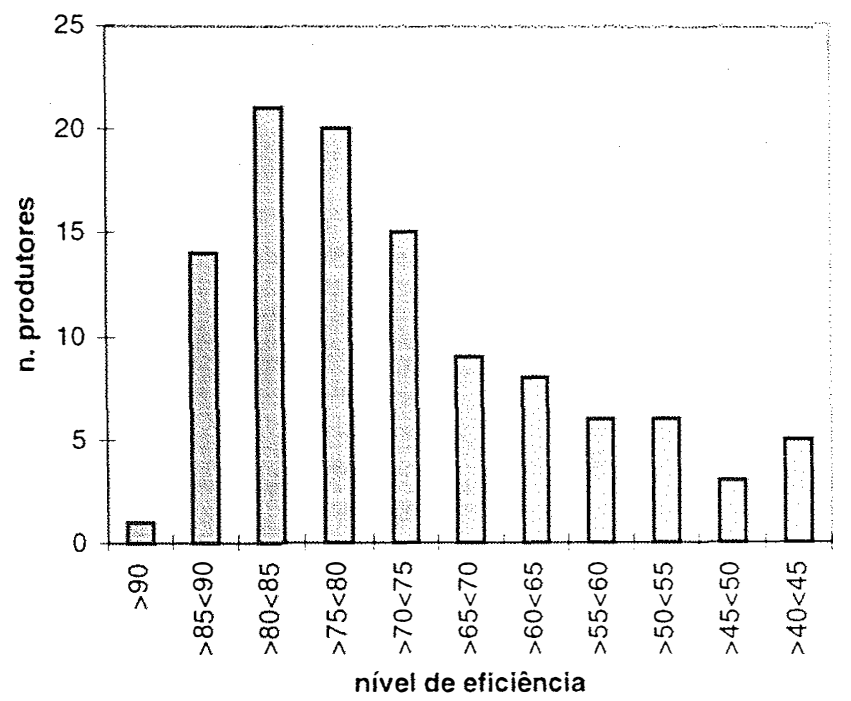

Fonte: Dados da Pesquisa

Os resultados mostram que o nível de eficiência técnica varia no intervalo de $41.47 \%$ a $93.09 \%$. Verifica-se também que $38 \%$ dos agricultores têm nível de eficiência entre $75 \%$ e $85 \%$.

A eficiência técnica média da amostra de produtores é de $73.08 \%$ (veja apêndice 4), indicando que existe ainda possibilidade de aumento da produtividade total dos fatores através da melhor utilização da tecnologia disponível.

O conhecimento de variáveis relacionadas com os níveis de eficiência técnica encontrados é, sem dúvida, importante. Assim sendo, são apresentados, nas Tabelas 5 e 6, os resultados do modelo de Tobit ${ }^{8}$, procurando relacionar os níveis de eficiência técnica com variáveis

\footnotetext{
${ }^{8}$ Foi utilizado o programa estatístico LIMDEP para estimar •s modelos TOBIT.
} 
representativas de capital humano: educação formal, extensão pública e privada, experiência e acesso à informação técnica (rádio).

Tabela 5. Estimativa dos parâmetros do Modelo Tobit com as variáveis: experiência, escolaridade, rádio, extensão pública e extensão privada, $1989 / 90 .(\mathrm{n}=108)$.

\begin{tabular}{|c|c|c|}
\hline Variável & Coeficientes & Estatística"t" \\
\hline Intercepto & $65.1144^{\star}$ & 21.713 \\
\hline Experiência & $3.2581 * * *$ & 1.275 \\
\hline Escolaridade & $0.3094^{\mathrm{NS}}$ & 0.127 \\
\hline Rádio & $5.9232 * *$ & 2.304 \\
\hline Extensão pública & $0.9675^{\mathrm{NS}}$ & 0.279 \\
\hline Extensão privada & $8.2288^{\star}$ & 2.984 \\
\hline LFMV & -421.1149 & \\
\hline Qui Quadrado & $13.56 \star \star$ & \\
\hline $\begin{aligned} \text { Fonte: } & \text { Dados da pesquisa } \\
\text { Nota: } & \star \text { significativo } 18 \\
& \star \star \text { significativo ao n } \\
& \star \star \star \text { significativo ao } \\
& \text { NS não siginificativo } \\
& \text { LFMV Logarítimo da Fu }\end{aligned}$ & $\begin{array}{l}0 \\
\text { xima }\end{array}$ & \\
\hline
\end{tabular}

Tabela 6. Estimativa dos parâmetros do modelo Tobit com as variáveis: experiência, escolaridade 1, rádio, extensão pública e extensão privada, 1989/90. $(n=108)$.

\begin{tabular}{|c|c|c|}
\hline Variável & Coeficientes & Estatística "t" \\
\hline Intercepto & $63.6193^{\star}$ & 20.422 \\
\hline Experiência & $3.6678 * \star *$ & 1.418 \\
\hline Escolaridadel & $2.0543^{\mathrm{NS}}$ & 0.834 \\
\hline Rádio & $6.0611 * \star$ & 2.455 \\
\hline Extensão pública & $1.3906^{\mathrm{NS}}$ & 0.400 \\
\hline Extensão privada & $8.6050 *$ & 3.098 \\
\hline LFMV & -420.7765 & : \\
\hline Qui Quadrado & $14.32 * \star$ & \\
\hline 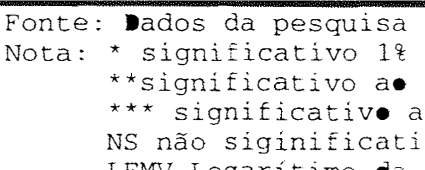 & $15 \%$ & \\
\hline
\end{tabular}


Como se pode observar, foram testados dois modelos. No primeiro foram consideradas as variáveis experiência, educação, extensão pública, extensão privada e rádio. No segundo, consideraram-se as mesmas variáveis, entretanto, a variável educação foi especificada de forma diferente, isto é, considerou-se a especificação de dummy igual a 1 para 4 anos ou mais de estudo formal.

Os resultados encontrados nos dois modelos são similares. Embora os sinais esperados dos parâmetros tenham sido os esperados, somente as variáveis experiência, extensão privada e rádio foram estatisticamente significativas. Isto é, as diferenças encontradas nos níveis de eficiência técnica são explicadas por essas variáveis. O teste de significância conjunta das variáveis, como sugerido por Hussain et al. (1994), é indicado pela estatística qui-quadrado. O valor de qui-quadrado calculado, nos dois modelos, foi superior ao tabelado ao nível de 5\%, o que permite concluir que os parâmetros estimados são conjuntamente diferentes de zero.

De forma geral pode-se inferir, portanto, que entre as variáveis analisadas, a experiência e a extensão privada, assim como fontes não convencionais de informação (rádio) tiveram impacto sobre os níveis de eficiência técnica da amostra. Tais resultados são coerentes com os registrados em outros estudos.

No que se refere à educação, as evidências empíricas disponíveis não estabelecem um padrão claro. Alguns estudos encontraram efeito positivo e estatisticamente significativo. Entre esses, pode-se citar os de Belbase \& Grabowski (1985); Kalirajan \& Shand (1986) e Phillips \& Marble (1986). Entretanto, outros trabalhos 
não encontraram efeito positivo da educação, como os de Bravo-Ureta \& Evenson (1994) e Kalirajan (1984, 1991).

Duas possíveis explicações podem ser atribuídas a essa dicotomia de evidências. A primeira reside no fato de que são necessários pelo menos quatro anos de estudo formal para que seja evidenciada alguma relação entre eficiência técnica e escolaridade. É o chamado threshold effect. Ou seja, é necessário um nível de escolaridade mínimo para que esta variável possa desempenhar papel ativo na promoção da eficiência. Este argumento, contudo, não parece ser válido no presente estudo, já que os produtores analisados têm um elevado grau de escolaridade; a média da amostra é de 8 anos (ver apêndice 5).

A segunda explicação refere-se ao fato do efeito da educação ser mais significativo sobre a eficiência alocativa do que sobre a eficiência técnica. Welch (1970), em excelente artigo, argumenta que a educação aumenta a produção e a produtividade de três maneiras distintas:

i) pela melhoria da habilidade do agricultor, permitindo-o obter maior produção com uma dada quantidade de insumos (efeito-trabalhador);

ii) pelo aumento das possibilidades do agricultor obter, entender e utilizar novos insumos e práticas modernas (efeito-alocativo); 
iii) pela possibilidade de determinação dos tipos e quantidades dos fatores a serem utilizados na função de produção (efeito insumo-seleção). Os agricultores com maior nível educacional podem adaptar melhor seus planos de produção à mudanças de preços dos insumos e, por isso, serão mais hábeis em identificálos e utilizá-los corretamente.

Assim, a educação tem um efeito direto sobre a eficiência técnica via efeito-trabalhador e tem um efeito sobre a eficiência alocativa, via efeitos alocativo e seletivo.

Segundo alguns autores, $\bigcirc$ efeito alocativo da educação é mais significativo. Pudasaini $(1983)^{9}$ estimou o efeito da educação na agricultura do Nepal. O autor encontrou resultados que corroboram o mencionado acima, ou seja, o efeito alocativo da educação foi muito mais significativo do que o efeitotrabalhador. Em outras palavras, a educação contribui mais pela melhoria da habilidade alocativa do que pela eficiência técnica. Huffman (1974) também encontrou resultados que evidenciam este fato. Ram (1980) sugere que a educação e os serviços de extensão têm um efeito positivo sobre a eficiência alocativa de produtores na Índia. E Kumbhakar \& Bhattacharya (1992) também

\footnotetext{
${ }^{9} \mathrm{O}$ autor na realidade não encontrou um efeito significativo da variável educação sobre a produção, no que se refere ao efeito-trabalhador (ver pág. 512). O parâmetro desta variável foi positivo. mas não estatisticamente significativo. Ainda assim, o autor estimou o efeito-trabalhador da educação.
} 
encontraram efeito positivo da educação sobre a eficiência alocativa.

Bravo-Ureta \& Pinheiro (1993) ressaltam que nos trabalhos empíricos que procuram investigar a influência de variáveis sócio-econômicas sobre os níveis de eficiência, a relação mais robusta é com a extensão e o acesso à informação. Essa evidência pode ser encontrada nos trabalhos de Kalirajan (1981, 1984, 1991); Kalirajan \& Flinn (1983); Kalirajan \& Shand (1986); Ray (1985); Muller (1974), Shapiro \& Muller (1977). Logo, os resultados encontrados nesta pesquisa parecem coerentes e consistentes com o conhecimento disponível.

Com efeito, os serviços de extensão privada têm o objetivo explícito de divulgar técnicas que deslocam para cima a função de produção. A partir de contatos com os serviços de extensão, os produtores têm maior acesso ao conhecimento técnico e podem, desta forma, produzir com maior eficiência técnica.

Neste sentido, convém lembrar que, nesta pesquisa, a influência da extensão pública sobre o nível de eficiência técnica não foi significativa.

Este resultado, não parece contraditório, nem surpreendente, principalmente quando se considera que a amostra em estudo é de produtores modernos. Sobre o assunto, Alves e Contini (1992) ressaltam que a importância da extensão privada cresceu com o desenvolvimento agrícola do país e é muito especializada em transferência de tecnologia. Por seu turno, a extensão pública é principalmente destinada à organização dos agricultores e a aspectos 
sociais. Ainda segundo esses autores, no Brasil, nas regiões Centro-Oeste, Sudeste e sul, a presença da extensão privada, representada por firmas de insumos modernos, agroindústrias, cooperativas e organizações especializadas em planejamento, já é uma realidade.

Ponto interessante a ressaltar é a elevada significância da variável rádio na explicação do nível de eficiência técnica. Esse é um caminho ainda pouco explorado empiricamente, mas é um resultado em favor do enorme poder que a comunicação de massa passou (e tem ainda) a desempenhar na modernização da agricultura brasileira.

Finalmente, a variável experiência também é importante na explicação dos níveis de eficiência técnica dos agricultores. Isto reforça a argumentação, explicitada na literatura do learning by doing. O aprender fazendo é uma vigorosa fonte para a aquisição de novos conhecimento e, por isso mesmo, deve ser considerada na formulação de políticas de desenvolvimento. 


\section{CONCLUSÃO}

Os resultados desta pesquisa não rejeitam a hipótese inicial de que ainda há possibilidade de aumentar a produtividade total dos fatores com a melhoria da eficiência técnica no segmento representativo da agricultura comercial brasileira. O nível médio de eficiência técnica encontrado é 73,08\%.

Sem dúvida, este nível médio de eficiência não é baixo, mas indica que, no curto prazo, ganhos adicionais de produtividade podem ser obtidos com o melhor desempenho técnico dos agricultores, levando-os a uma proximidade maior da fronteira de produção.

No que se refere à segunda hipótese, qual seja, de o nível de eficiência técnica não estar uniformemente distribuído entre os agricultores, não se pode também rejeitá-la, pois os níveis de eficiência variam no intervalo de $41 \%$ a 93\%. E mais, enquanto 52\% dos agricultores da amostra têm eficiência acima de 75\%, apenas um deles atinge o nível de 93\%. Ademais, 34\% dos produtores apresentam nível inferior a $70 \%$, situando-se, portanto, 
abaixo da eficiência média. Observa-se, assim, heterogeneidade na distribuição de tais índices.

$\mathrm{Na}$ busca de identificação de possíveis variáveis que possam contribuir para o melhor desempenho dos agricultores modernos, os modelos testados apresentam resultados interessantes. Dentre as variáveis analisadas, extensão privada, experiência na agricultura e fontes alternativas de informação (rádio) são importantes para explicar os níveis encontrados de eficiência técnica.

Os produtores que tiveram maior contato com os serviços de extensão privada apresentaram níveis mais altos de eficiência. Isso evidencia o importante papel que tais serviços podem desempenhar na agricultura comercial. Possivelmente, ao adquirirem insumos, os produtores têm acesso a informações essenciais sobre como utilizá-los corretamente.

O conhecimento acumulado pela experiência na produção agrícola é outra variável explicativa do nível de eficiência dos produtores. Em outras palavras, as idéias sobre o processo de learning by doing, tão bem defendidas por Arrow e Rosen, são confirmadas nesta pesquisa.

A influência positiva de fontes alternativas de informação sobre a eficiência técnica é outra conclusão que merece destaque. Programas de rádio sobre técnicas e processos produtivos merecem maior atenção e prioridade na formulação de políticas públicas.

Entretanto, a educação, medida pela escolaridade do produtor rural, não apresenta efeito estatisticamente significativo sobre o nível de eficiência. 
Uma das possíveis explicações para isto está fundamentada no fato, documentado empiricamente, de a educação ter maior impacto sobre a eficiência alocativa.

Atualmente, os ganhos de produtividade são essenciais à garantia da competitividade de nossa agricultura, razão pela qual esforços destinados à melhoria da eficiência técnica e da eficiência econômica são exigidos.

Tudo indica que o processo de modernização da agricultura brasileira, além de ser parcial e seletivo, atingindo grupos especiais de agricultores e regiões (tal como analisado no presente estudol, poderá realizar ganhos de eficiência com a implementação de políticas efetivas de difusão de inovações.

No cenário atual, a constatação de ineficiência técnica entre produtores representativos da agricultura moderna sugere que esforços sejam destinados também à melhoria do desempenho deste segmento. Certamente, a questão da informação técnica e econômica é de fundamental importância. Além de estimular, divulgar e assegurar que novas tecnologias sejam utilizadas faz-se necessário cuidar para que elas sejam usadas de modo eficiente. Este trabalho sugere que a conquista de eficiência técnica pode constituir uma fonte substantiva de ganhos de produtividade.

Entretanto, a constatação de ineficiência técnica no processo produtivo não significa que todos os instrumentos de política agrícola devam ser direcionados exclusivamente para a eliminação de tal ineficiência. 
Evidentemente, os ganhos de produtividade advindos da geração de novas tecnologias são, e continuarão a ser, um dos principais determinantes do crescimento econômico.

Uma sugestão para futuras pesquisas seria a obtenção de estimativas de eficiência alocativa nos segmentos moderno e tradicional de nossa agricultura. Certamente, a estimativa desta eficiência forneceria elementos adicionais para o melhor entendimento do processo de modernização da agricultura.

Finalizando, três conclusões deste trabalho precisam ser enfatizadas:

i) os produtores comerciais/modernos da amostra não conseguem explorar a tecnologia disponível em toda sua plenitude, em razão da presença de ineficiência técnica. A ineficiência técnica média da amostra é de $26,92 \%$;

ii) o nível de eficiência técnica não é uniformemente distribuído entre os agricultores da amostra. Aproximadamente $34 \%$ deles apresentam níveis de eficiência técnica abaixo da média estimada; e,

iii) extensão privada e informação técnica são variáveis-chave para a melhoria da eficiência técnica. Em segundo plano, mas não menos importante, está a experiência do produtor rural. 


\section{REFERÊNCIAS BIBLIOGRÁFICAS}

AFRIAT, S.N. Efficiency estimation of production functions. International Economic Review, V.13, n.3, p. 568-598, 1972 .

AIGNER, D.J.; CHU, S.F. On estimating the industry production function. American Economic Review, V.58, n.4, p. 826-839, 1968 .

AIGNER,D.J.; LOVELL, C.A.K.; SCHMIDT, P.J. Formulation and estimation of stochastic frontier production models. Journal of Econometrics, v.6, n.1, p.21-37, 1977.

ALI, M.; FLINN, J.C. Profit efficiency among basmati rice producers in pakistan punjab. American Journal of Agricultural Economics, V.71, n.2, p.303-310, 1989.

ALVES, E.R.A. Reflexões sobre política agrícola. Revista de Economia e Sociologia Rural, v.31, n.2, p.91-102, 1993.

ALVES,E.R.A.; PASTORE, J. Uma nova abordagem para a pesquisa agrícola no Brasil. Revista de Economia Rural, v.15, n.1, p.235-256, 1977 . 
ALVES, E.R.A.; CONTINI, E. A modernização da agricultura brasileira. In: BRANDÃO, A.S.P. (Ed.). Os principais problemas da agricultura brasileira: análise e sugestões. 2.ed. Brasília: PNPE/IPEA, p.49-98. 1992.

ALVES, E.R.A.; PASTORE, A.C.A. A política agrícola no Brasil e a hipótese da inovação induzida. In: ALVES, E. R.A. et al. Coletânea de trabalhos sobre a EMBRAPA. Brasília: EMBRAPA, p.9-20, 1980.

ARAÚJO, P.F.C. O crédito rural e sua distribuição no Brasil. Estudos Econômicos, V.13, n.2, 1983.

ARAÚJo, P.F.C.; BARRos, G.S.C.; PAIVA, R.M.; AlmeidA, A.; PERES, A.R.P. Características da agricultura das regiões estudadas: primeiros resultados de campo. Piracicaba: CEPEA/FEALQ, 1990. (Relatório de pesquisa n.1).

ARNADE, C.A. Productivity and technical change in Brazilian agriculture. United states Department of Agriculture. Economic Research Service: Technical Bulletim, n.1811, p.23, 1992.

ARROW, K.J. The economic implication of learning by doing. Review Economic studies, v.29, n.2, p.155-173, 1962.

AZHAR, R.A. Education and technical efficiency during the green revolution in pakistan. Economic Development and Cultural Change, v.39, n.3, p.651-662, 1991.

BAGI, F.S. A relationship between farm size and technical efficiency in west tennesse agriculture. Southern Journal Agricicultural Economic, V.14, n.1, p.139-144, 1982 a. 
BAGI, F.S. Economic efficiency of sharecropping: reply and some further results. Malayan Economic Review, v.27, n.1, p. 86-95, $1982 \mathrm{~b}$.

BAGI, F.S. Stochastic frontier production function and farm-level technical efficiency of full-time and parttime farms in West Tennessee. Journal of Agricultural Economics, V.6, n.1, p.48-55, 1984 .

BAGI, F.S.; HUANG, C.J. Estimating production technical efficiency of individual farms in tennessee. Canadian Journal of Agricultural Economics, v.31, n.2, p.249-256, 1983 .

BARROS, G.S.C. A transição na política agrícola brasileira. In: CONGRESSO BRASILEIRO DE ECONOMIA E SOCIOLOGIA RURAL, 36., Poços de Caldas, 1998. Anais. Brasília: SOBER, 1998. p.1-19.

BARROS, J.R.M. Transição e descontinuidade no crescimento agrícola. In: DIAS, G.L.S.; BARROS, J.R.M. Fundamentos de uma nova politica agrícola. Brasilia: CFP, 1983. 39p. (Coleção Análise e Pesquisa, 26).

BARROS, J.R.M.; PASTORE, A C.; RIZZIERI, J.A B. A evolução recente da agricultura brasileira. In: BARROS, J.R.M.; GRAHAM, D.H. Estudos econômicos da agricultura brasileira. São Paulo, USP/IPE, 1977. (Monografias, 9).

BARROS, J.R.M. Política e desenvolvimento agrícola no Brasil. In: VEIGA, A. (Coord.) Ensaios sobre politica agrícola brasileira. São Paulo: Secretaria da Agricultura, 1979 . p.9-35. 
BARROS, J.R.M.; PASTORE, A.C.; RIZZIERI, J.B. Participação dos índices de produtividade da terra entre os componentes tecnológico e alocativo. Pesquisa e Planejamento Econômico, V.6, n.3, p.755-766, dez. 1976.

BARROS, G.C.S.; BERES, N.A. , MALHEIROS, P.C.F. Gastos públicos na agricultura: tendências e prioridades. Estudos de política agrícola, n.2, p.7-20, 1993.

BATTESE, G.E. Frontier production functions and technical efficiency; a survey of empirical applications in agricultural economics. Agricultural Economics, v.7, n.3, p. 185-208, 1992 .

BATTESE, G.E.; COELLI, T.J. Prediction of firm-level technical efficiencies with a generalized frontier production function and panel data. Journal of Econometrics, v.38, n.3, p.387-399, 1988.

BATTESE, G.E.; CORRA, G.S. Estimation of a production frontier model: with application to the pastoral zone of eastern Austrália. Australian Journal of Agricultural Economics, V.21, n.2, p.169-179, 1977.

BATTESE, G.E.; TESSEMA, G.A. Estimation of stochastic frontier production functions with time varuing parameters and techrical efficiencies using panel data from India villages. Armidale: University of New England, 1992. 31p. (Working Paper Econometrics Applied Statistics, 64).

BELBASE, K.; GRABOWSKI, R. Technical efficiency in nepalese agriculture. Journal of Development Areas, v.19, n.4, p.515-525, 1985 . 
BIRKHAEUSER, D.; EVENSON, R.E.; FEDER, G. The economic impact of agricultural extension. Economic Development and Cultural Change, V.39, n.3, p.607-649, 1991.

BRAVO-URETA, B.E.; EVENSON, R.E. Efficiency in agricultural production: the case of peasant farmers in eastern Paraguay. Agricultural Economics, V.10, n.1, p. $27-37,1994$.

BRAVO-URETA, B.E.; PINHEIRO, A.E. Efficiency analysis of developing country agriculture: a review of the frontier literature. Agricultural and Resource Economics Review, V.22, n.1, p.88-101, 1993 .

BRAVO-URETA, B.E.; PINHEIRO, E. Technical economic and allocative efficiency in peasant farming: evidence from the Domician Republic. The Developing Economies, V.35, n.1, p.48-67, 1997 .

BRAVO-URETA, B.E.; RIEGER, L. Alternative production frontier methodologies and dairy farm efficiency. Journal of Agricultural Economics, V.41, n.2, p.215-226, 1990.

BRAVO-URETA, B.E.; RIEGER, L. Dairy farm efficiency measurement using stochastic frontiers and neoclassical duality. American Journal of Agricultural Economics, v.73, n.2, p.421-428, 1991 .

CAVES, R.E.; BARTON, D.R. Efficiency in U.S. manufacturing industries, Cambridge, Mass: MIT Press, 1991.

CUINHA, A.S.; DAGUER, R.J. Crescimento agrícola: área vs produtividade. In: CONGRESSO BRASILEIRO DE ECONOMIA E SOCIOLOGIA RURAL, 20. Curitiba, 1982. Anais. Brasília: SOBER, 1982. p.329-81. 
DAVIDSON, J.; MACKINNON, J. Estimation and inference in econometrics. New York: Oxford University Press, 1993. $874 \mathrm{p}$.

DUGGER, R. An aplication of bounded nonparametric estimating functions to the analysis of bank cost and production. Chaphel Hill, 1974. Thesis (Ph.D.) University of North Carolina.

FARREL, M.J.; FIELDHOUSE, M. Estimating efficient production under increasing return to scale. Journal of the Royal statistical society, v.23, n.2, p.252-267, 1962 .

FARRELL, M.J. The measurement of productive efficiency. Journal of Royal statistical society, v.19, n.2, p.253281,1957 .

FEDER, G.; JUST, E.R.; ZILBERMAN, D. Adoption of agricultural innovations in developing countries: a survey. Economic Development and Cultural Change, V.33, n.2, p.255-297, 1985 .

FERREIRA, L.R. Produtividade e investimentos públicos na agricultura brasileira. In: CONGRESSO BRASILEIRO DE ECONOMIA E SOCIOLOGIA RURAL, 29., Campinas, 1991. Anais. Brasília: SOBER, 1991. p.504-12.

GASQUES, J.G.; VILLA VERDE, C.M. Crescimento da agricultura brasileira e a politica agrícola nos anos oitenta. Agricultura em são Paulo, V.37, n.1, p.183-204, 1990 .

GASQUES, J.G.; VILLA VERDE, C.M. Prioridades e orientação dos gastos públicos em agricultura no Brasil. Brasília: IPEA, 1995. (Texto para Discussão, n.360) 
GASQUES, J.G.; VILLA VERDE, C.M. Recursos para a agricultura e orientação dos gastos públicos. Brasília: IPEA, 1991. (Texto para Discussão, n.229).

GOOD, D.H.; NADIRI, M.I.; ROLLER, L.H. e SICKES, R.C. Efficiency and productivity growth comparisons of European U. S. air carriers: a first look at the data. Journal of Productivity Analysis v4, n.1/2, p.115-25, 1993.

GOMES, R.S. Socioeconomics, management and istitutional determinants of technical efficiency: the case of small producers in irrigated agriculture in northeast Brazil. (Arizona), 1986. 151p. Thesis (Master) - Department of Agricultural and Resource Economics.

GREENE, W.H. A gamma-distributed stochastic frontier model. Journal of Econometrics, V.46, n.1, p.143-163, 1990 .

GREENE, W.H. Econometric analysis. 3.ed. Englewood Cliffs: Prentice Hall, 1997. 791p.

GREENE, W.H. LIMDEP: user's manual and reference guide. New York: Econometric Software, 1991.

HAYAMI, Y.; RUTTAN, V.W. Agricultural development: an international perspective. Baltimore: Johns Hopkins University Press, 1985. $367 \mathrm{p}$.

HUANG, C.J.; BAGI, F.S. Technical efficiency on individual farms in Northwest India. Southern Economic Journal, v.51, n.1, p.108-115, 1984 .

HUFFMAN, W.E. Decision making: the role of education. American Journal of Agricultural Economics, V.56, n.1, p. $85-97,1974$. 
HUSSAIN, S.S.; BYRLEE, D.; HEISUY, P.W. Impacts of training and visit extension systemon farmer's knowledge and adoption of technology: evidence from Pakistan. Agricultural Economics, v.10, n.1, p.39-47, 1994.

JONDROW, J.; LOVELL, C.A.K.; MATEROV, I.S.; SCHMIDT, P. On the estimation of technical inefficiency in the stochastic frontier production function model. Journal of Econometrics, V.19, n.2/3, p.232-238, 1982.

JUDGE， G.G.; HILL, R.C.; GRIFFITHS, W.E.; LEITKEPOHL, H.; LEE, T.C. Introduction to the theory and pratice of econometrics. 2.ed. New York: John Wiley \& Sons, 1988. $1024 \mathrm{p}$.

KALIRAJAN, K. Farm specific technical efficiencies and development policies. Journal of Economics studies, v.11, n.3, p.3-13, 1984 .

KALIRAJAN, $\mathrm{K}$. An econometric analysis of yield variability in paddy production. Canadian Journal of Agricultural Economics, V.29, n.2, p.283-294, 1981.

KALIRAJAN, $K$. The importance of efficient use in the adoption of technology: a micro panel data analysis. Journal of Productivity Analysis, n.2, p.113-126, 1991.

KALIRAJAN, K.; SHAND, R.T. Estimating location-specific and firm-specific technical efficiency: an analysis of Malaysian agriculture. Journal Economic Development, V.11, n.1, p.147-160, 1986.

KALIRAJAN, $\mathrm{K}$. On measuring the contribution of human capital to agricultural production. Indian Economic Review, v.24, p.247-261, 1989. 
KALIRAJAN, K.; FLINN, J.C. The measurement of farmspecific technical efficiency in Pakistan. Journal of Applied Economic, V.2, n.1, p.167-180, 1983.

KOOP, R.J. The measurement of productive efficiency: a reconsideration. The Quarterly Journal of Economics, v.96, n.3, p.477-503, 1981 .

KOOP, R.J.; DIEWERT, W.E. The Decomposition of frontier cost function deviations in to measures of technical and allocative efficiency. Journal Econometrics, V.20, n.2, p. 319-331, 1982 .

KOOP, R.J.; SMITH, V.K. Frontier production function estimates for steam eletric generation : a comparative analysis. Southern Economic Journal, v.47, n.4, p.10491059,1980 .

KUMBHAKAR, S.C.; BHATTACHARYA, A. Price distorcion and resource use efficiency in Indian agriculture: a restricted profit function approach. Review of Economics and statistics, V.74, n.2, p.231-239, 1992.

KUMBHAKAR, S.C.; HJALMARSSON, - Technical efficiency and technical progress in swedish dairy farms. In: FRIED, H.O; LOVELL, C.A.K.; SCHMIDT, P. The measurement of productive efficiency: techniques and aplications. New York: Oxford, 1993. 426p.

KUZNETS, S. Modern economic growth: rate, structure and spread. New Haven: Yale University Press, 1966. 529p.

LINGARD, J.; CASTILLO, L.; JAYASURIYA, S. Comparative efficiency of rice farms in Central Luzon, the philippines. Journal Agricultural Economic, v.34, n.2, p.163-173, 1983 . 
LIPTON, M. Education and farm efficiency: comment. Economic Development and Cultural Change, V.34, n.1, p. 167-168, 1985 .

LOOCKEED, M.; JAMISON, D.; LAU, L. Farmer education and farm efficiency: a survey. Economic Development and Cultural Change, V.29, n.1, p.27-76, 1980.

MADDALA, G.S. Introduction to econometrics. New York: Macmillan Publishing Company, 1988. 427p.

MEEUSEN, W.; BROECK, J. Van Den. Efficiency estimation from cobb-douglas production functions with composed error. International Economic Review, V.18, n.2, p.435444,1977 .

Moock, P. Education and technical efficiency in small farm production. Economic Development and Cultural Change, V.29, n.4, p.723-739, 1985 .

MULLER, J. Efficiency frontiers for industrial establishments of different sizes: explorations in economic research. Occasional paper of the National Bureau of Economic Research, n.3, p.379-407, 1976.

MULLER, J. On sources of measured technical efficiency: the impact of information. American Journal of Agricultural Economics, v.56, n.4, p.730-738, 1974.

MUNHOZ, D.G. Economia Agrícola: agricultura uma defesa dos subsídios. Petrópolis: Vozes, 1982.

NEFF, D.L.; GARCIA, P.; NELSON, C.H. Technical efficiency: a comparison of production frontier methods. Journal of Agricultual Economics, v.44, n.3, p.479-489, 1993. 
PATRICK, G.F. Fontes de crescimento da agricultura brasileira: o setor de culturas. In: CONTADOR, C.R. Tecnologia e desenvolvimento agrícola. Brasília: IPEA/INPES, P.89-110, 1975.

PHILLIPS, J.M.; MARBLE, R.P. Farmer education and efficiency: a frontier production function approach. Economics of Education Review, v.5, n.3, p.257-264, 1986. PUDASAINI, S.P. The effects of education in agriculture: evidence from Nepal. American Journal of Agricultural Economics, V.65, n.3, p.503-516, 1983.

RAM, R. Role of education production: a slightly new approach. Quarterly Journal of Economic, v.95, n.2, p. 365-373, 1980 .

RAY, S.C. Measurement and test of efficiency of farms in linear programming models: a study of west bengal farms. Oxford Bulletim of Economics and statistics, V.47, n.4, p. 371-386. 1985 .

RICHMOND, J. Estimating the efficiency of production. International Economic Review, V.15, n.4, p.515-521, 1974 .

ROSEN, S. Learning by experience as joint production. Quarterly Journal of Economic, v.86, n.3, p.366-382, 1972 .

SCHMIDT, P. Frontier production functions. Econometric Reviews, V.4, n.2, p.289-328, 1986.

SCHMIDT, P.; LOVELL, C.A.K. Estimating technical and allocative inefficiency relative to stochastic production and cost frontiers. Journal of Econometrics, V.9, n.3, p. 343-366, 1979 . 
SCHUH, G.E. A modernização da agricultura brasileira: uma interpretação. In: CONTADOR, C.R. Tecnologia e desenvolvimento agrícola. Brasilia: IPEA/INPES, p.7-45, 1975. (Série Monografia, 17).

SCHUH, G.E. The theory, empirical evidence, and debates on agricultural development issues in Latin American: a selective survey. S.I: s.n., 1990. cap.IX, p.580-642: Human capital: a policy perspective.

SCHULTZ, T.W. Transforming traditional agriculture. New Haven: Yale University Press, 1964. 212p.

SEIFORD, L.M.; THRALL, R. Recent development in DEA: the mathematical programming approach to frontier fnalysis. Journal of Econometrics, V.46, n.1/2, p.7-38, 1990.

SEITZ, W.D. The measurement of efficiency relative to a frontier production function. American Journal of Agricultural Economics, V.52, n.4, p.505-511, 1970.

SEITZ, W.D. Productive efficiency in the steam-eletric generating industry. Journal of Political Economy, V.79, n.4, p.876-886, 1971 .

SHAPIRO, K.H. Efficiency differentials in peasant agriculture and their implications for development policies. Journal of Development studies, V.19, n.1, p. 179-190, 1983 .

SHAPIRO, K.H.; MULLER, J. Sources of technical efficiency: the role of modernization and information. Economic Development and Cultural Change, v.25, n.2, p.293-310, 1977 . 
SILVA, C.R.L.; CARVALHO, M.A.; MARGARIDO, M.A.; FERREIRA, C.R.R.P.T. O processo de modernização e o uso de tratores na agricultura brasileira. Agricultura em são Paulo, v.37, n.3, p.119-128, 1990.

SQUIRES, D.; TABOR, S. Technical efficiency and future production gains in indonesian agriculture. Developing Economies, V.24, n.3, p.258-270, 1991.

STEVENSON, R.E. Likelihood functions for generalized stochastic frontiers estimations. Journal of Econometrics, V.13, n.1, p.57-66, 1980.

TAYLOR, T.G.; DRUMMOND, H.E.; GOMES, A.T. Agricultural credit programs and production efficiency: an analysis of traditional farming in south eastern Minas Gerais, Brazil. American Journal of Agricultural Economics, V.68, n.1, p.110-119, 1986 .

TAYLOR, T.G.; SHONKWILER, J.S. Alternative stochastic specifications of the frontier production function in the analysis of agricultural credit programs and technical efficiency. Journal of Development Economics, V.21, n.1, p.149-160, 1986 .

TIMMER, C.P. Using a probabilistic frontier production function to measure technical efficiency. Journal of Political Economy, v.79, n.4, p.776-794, 1971.

TODD, D. The relative efficiency of small and large firms, committee of inquiry on small firms. Research Report, n.18, 1971 .

TUPY, O. Fronteiras estocásticas, dualidade neoclássica e eficiência econômica na produção de frangos de corte. Piracicaba, 1996. 91p. Tese (Doutorado) - Escola 
Superior de Agricultura Luiz de Queiroz, Univerdade de São Paulo.

VEIGA, A. Agricultura e processo político: o caso

brasileiro. Revista de Economia e Sociologia Rural, V.29, n. 4, p. 285-334, 1991 .

WELCH, F. Education in production. Journal of political Economy, V.78, n.1, p.35-39, 1970.

ZELLNER, A.J.; KMENTA, J.; DRÈZE, J. Specification and estimation of cobb-douglas production function models. Econometrica, v.34, n.4, p.784-795, 1966. 


\section{APÊNDICE 1}

Demonstração da igualdade entre a especificação normal-truncada e meio-normal quando $\mu=0$ 


\section{Especificação normal-truncada e meio-normal}

Este apêndice tem como objetivo demonstrar que a especificação norma-truncada é igual à especificação meio-normal quando $\mu=0$.

Esta demonstração será feita para $f(u), E(u), \operatorname{Var}(u), F(\varepsilon)$ e $E(u / \varepsilon)$

Considerando-se inicialmente que $u$ tenha uma distribuição normal-truncada, então:

Para $f(u)$

$$
f(u)=\frac{\exp \left[\frac{-1}{2}(u-\mu)^{2} / \sigma_{u}^{2}\right]}{\sqrt{2 \pi} \sigma_{u}\left[1-F\left(\mu / \sigma_{u}\right)\right]}
$$

No caso da distribuição meio-normal $\mu=0$, então a equação acima fica:

$$
\begin{aligned}
& f(u)=\frac{\exp \left[\frac{-1}{2} u^{2} / \sigma_{u}^{2}\right]}{\sqrt{2 \pi} \sigma_{u}[1-F(0)]}= \\
& f(u)=\frac{\exp \left[\frac{-1}{2} u^{2} / \sigma_{u}^{2}\right]}{\sqrt{2 \pi} \sigma_{u}(1 / 2)}=
\end{aligned}
$$




$$
\begin{aligned}
& f(u)=\frac{2 \exp \left[\frac{-1}{2} u^{2} / \sigma_{u}^{2}\right]}{\sqrt{2 \pi} \sigma_{u}}= \\
& f(u)=\frac{\sqrt{2}}{\sqrt{\pi} \sigma_{u}} \exp \left[\frac{-1}{2} u^{2} / \sigma_{u}^{2}\right], \text { que é igual a } f(u)
\end{aligned}
$$

para o caso meio-normal.

\section{Para $E(u)$}

No caso normal-truncado $E(u)$ é igual a:

$$
E(u)=\frac{\mu}{2}\left(1-F\left(\frac{\mu}{\sigma_{u}}\right)\right)^{-1}+\frac{\sigma_{u}}{\sqrt{2 \pi}}\left(1-F\left(\frac{\mu}{\sigma_{u}}\right)\right)^{-1} \exp \left(\frac{-1}{2}\left(-\frac{\mu}{\sigma_{u}}\right)^{2}\right)
$$

Como no caso meio-normal $\mu=0$, então:

$$
E(u)=\frac{\sigma_{u}}{\sqrt{2 \pi}}(1-F(0))^{-1} \exp (0)=
$$

$$
E(u)=\frac{\sigma_{u}}{\sqrt{2 \pi}}\left(1-\frac{1}{2}\right)^{-1}=
$$

$$
E(u)=\frac{2 \sigma_{u}}{\sqrt{2 \pi}}=
$$




$$
E(u)=\sigma_{u} \frac{\sqrt{2}}{\sqrt{\pi}}, \text { que é igual a } E(u) \text { quando } u
$$

tem uma distribuição meio-normal.

\section{Para Var $(u)$}

No caso da distribuição normal-truncada

$\operatorname{Var}(u)$ é:

$$
\begin{aligned}
& \operatorname{Var}(u)=\mu^{2} \frac{a}{2}\left(1-\frac{a}{2}\right)+\sigma_{u}^{2} \frac{a}{2}\left(\frac{\pi-a}{\pi}\right) \quad \text { onde } \\
& a=\left[1-F\left(\frac{\mu}{\sigma_{u}}\right)\right]^{-1}
\end{aligned}
$$

Fazendo $\mu=0$, tem-se para o caso meio-normal:

$$
\begin{aligned}
& a=[1-F(0)]^{-1} \\
& a=\left(1-\frac{1}{2}\right)^{-1} \\
& a=2
\end{aligned}
$$

Substituindo na equação da Variância, temse:

$$
\operatorname{Var}(u)=\sigma_{u}^{2} \frac{2}{2}\left(\frac{\pi-2}{\pi}\right)
$$




$$
\operatorname{Var}(u)=\sigma_{u}^{2}\left(\frac{\pi-2}{\pi}\right) \text {, que é igual a } \operatorname{Var}(u) \text { para a }
$$

distribuição meio-normal

\section{Para $f(\varepsilon)$}

No caso normal-truncado $f(\varepsilon)$ é igual a:

$$
f(\varepsilon)=\frac{1}{\sigma} f\left(\frac{\varepsilon-\mu}{\sigma}\right)\left[1-F\left(\frac{\mu}{\sigma \lambda}+\frac{\varepsilon \lambda}{\sigma}\right)\right]\left[1-F\left(\frac{\mu}{\sigma_{u}}\right)\right]^{-1}
$$

Para $\mu=0$, tem-se:

$$
\begin{aligned}
& f(\varepsilon)=\frac{1}{\sigma} f\left(\frac{\varepsilon}{\sigma}\right)\left[1-F\left(\frac{\varepsilon \lambda}{\sigma}\right)\right][1-F(0)]^{-1}= \\
& f(\varepsilon)=\frac{1}{\sigma} f\left(\frac{\varepsilon}{\sigma}\right)\left[1-F\left(\frac{\varepsilon \lambda}{\sigma}\right)\right]\left[1-\frac{1}{2}\right]^{-1}= \\
& f(\varepsilon)=\frac{2}{\sigma} f\left(\frac{\varepsilon}{\sigma}\right)\left[1-F\left(\frac{\varepsilon \lambda}{\sigma}\right)\right], \text { que é igual a } f(\varepsilon) \text { no }
\end{aligned}
$$

caso meio-normal.

Para $E\left(u_{j} / \varepsilon_{j}\right)$

No caso normal-truncado $E\left(u_{j} / \varepsilon_{j}\right)$ é igual a: 


$$
E\left(u_{j} / \varepsilon_{j}\right)=\sigma *\left\{\frac{f\left(\varepsilon_{j} \lambda / \sigma+\mu / \sigma \lambda\right)}{\left[1-F\left(\varepsilon_{j} \lambda / \sigma+\mu / \sigma \lambda\right)\right]}-\left(\frac{\varepsilon_{j} \lambda}{\sigma}+\frac{\mu}{\sigma \lambda}\right)\right\}
$$

No caso meio-normal $\mu=0$, então:

$$
E\left(u_{j} / \varepsilon_{j}\right)=\sigma_{*}\left[\frac{f\left(\varepsilon_{j} \lambda / \sigma\right)}{1-F\left(\varepsilon_{j} \lambda / \sigma\right)}-\frac{\varepsilon_{j} \lambda}{\sigma}\right]
$$

Para o cálculo da eficiência técnica média, tem-se, no caso de $u$ ter uma distribuição normal-truncada:

$$
E T=\left\{\frac{1-F\left[\sigma_{u}-\left(\mu / \sigma_{u}\right)\right]}{1-F\left(\mu / \sigma_{u}\right)}\right\} \exp \left(-\mu+\frac{1}{2} \sigma_{u}^{2}\right)
$$

Para $\mu=0$, tem-se:

$$
E T=\left\{\frac{1-F\left(\sigma_{u}\right)}{1-F(0)}\right\} \exp \left(\frac{1}{2} \sigma_{u}{ }^{2}\right)
$$




$$
\begin{aligned}
& E T=\frac{1-F\left(\sigma_{u}\right)}{1 / 2} \exp \left(\frac{1}{2} \sigma_{u}{ }^{2}\right) \\
& E T=2\left[1-F\left(\sigma_{u}\right)\right] \exp \left(\frac{1}{2} \sigma_{u}{ }^{2}\right) \text {, que é igual ao caso }
\end{aligned}
$$

meio-normal. 
APÊNDICE 2 .

Estimativas dos parâmetros da função de produção de fronteira estocástica com especificação normal-truncada para $u_{j}$ 
Tabela 7. Estimativas dos parâmetros da fronteira de produção estocástica Cobb-Douglas para amostra de agricultores comerciais do Brasil.

\begin{tabular}{|c|c|c|}
\hline \multicolumn{2}{|r|}{ Variáveis } & $\begin{array}{l}\text { Fronteira } \\
\text { cástica }\end{array}$ \\
\hline \multicolumn{2}{|c|}{ Intercepto } & $\begin{array}{l}7.9748 * \\
(8.326)\end{array}$ \\
\hline \multicolumn{2}{|l|}{ Terra } & $\begin{array}{l}0.4974 * \\
(7.829)\end{array}$ \\
\hline \multicolumn{2}{|c|}{ Trabalho } & $\begin{array}{r}0.1379 * \star \\
(2.265)\end{array}$ \\
\hline \multicolumn{2}{|c|}{ Gastos Insumos Modernos } & $\begin{array}{l}0.2668 * \\
(5.052)\end{array}$ \\
\hline \multicolumn{2}{|l|}{$\mu / \sigma_{u}$} & $\begin{array}{r}-0.2780^{\mathrm{ns}} \\
(-0.044)\end{array}$ \\
\hline \multicolumn{2}{|l|}{$\lambda$} & $\begin{array}{c}1.3289^{\text {ns }} \\
(0.970)\end{array}$ \\
\hline \multicolumn{2}{|l|}{$\sigma$} & $\begin{array}{l}0.4375^{\mathrm{ns}} \\
(0.922)\end{array}$ \\
\hline \multicolumn{2}{|l|}{ LFMV } & -38.8627 \\
\hline \multicolumn{3}{|c|}{ 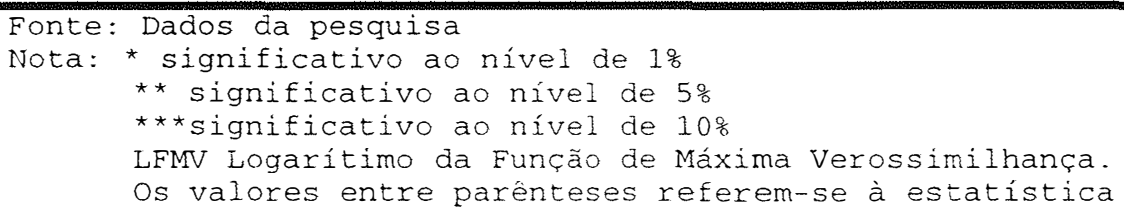 } \\
\hline
\end{tabular}


APÊNDICE 3

Estimativa da eficiência técnica por fazenda. 
Tabela 8. Estimativas de uj e da Eficiência Técnica por Fazenda.

\begin{tabular}{|c|c|c|}
\hline Região & $u_{j}$ & $\begin{array}{c}\text { Eficiência } \\
\text { Técnica } E\left(-u_{j}\right) \\
\end{array}$ \\
\hline Carazinho & 0.8802 & $41.47 \%$ \\
\hline Rio Verde & 0.8680 & $41.98 \%$ \\
\hline Rio Verde & 0.8229 & $43.92 \%$ \\
\hline Rio Verde & 0.8133 & $44.34 \%$ \\
\hline Rio Verde & 0.8097 & $44.50 \%$ \\
\hline Rio Verde & 0.7941 & $45.20 \%$ \\
\hline São Gabriel d'Oeste & 0.7660 & $46.49 \%$ \\
\hline São Gabriel d'Oeste & 0.7064 & $49.34 \%$ \\
\hline Rio Verde & 0.6849 & $50.41 \%$ \\
\hline São Gabriel d'Oeste & 0.6838 & $50.47 \%$ \\
\hline Carazinho & 0.6257 & $53.49 \%$ \\
\hline Rio Verde & 0.6142 & $54.11 \%$ \\
\hline Carazinho & 0.6106 & $54.30 \%$ \\
\hline Rio Verde & 0.5989 & $54.94 \%$ \\
\hline Rondonópolis & 0.5964 & $55.08 \%$ \\
\hline Rio Verde & 0.5766 & $56.18 \%$ \\
\hline Rio Verde & 0.5669 & $56.73 \%$ \\
\hline São Gabriel d'Oeste & 0.5611 & $57.06 \%$ \\
\hline Rondonópolis & 0.5420 & $58.16 \%$ \\
\hline Carazinho & 0.5114 & $59.97 \%$ \\
\hline Rio Verde & 0.5082 & $60.16 \%$ \\
\hline Rio Verde & 0.5036 & $60.44 \%$ \\
\hline Carazinho & 0.4879 & $61.39 \%$ \\
\hline São Gabriel d'oeste & 0.4822 & $61.74 \%$ \\
\hline Rondonópolis & 0.4778 & $62.01 \%$ \\
\hline Carazinho & 0.4757 & $62.14 \%$ \\
\hline Rio Verde & 0.4746 & $62.21 \%$ \\
\hline
\end{tabular}


Continuação

\begin{tabular}{|c|c|c|}
\hline Região & $u_{j}$ & $\begin{array}{c}\text { Eficiência } \\
\text { Técnica } \mathrm{E}\left(-\mathrm{u}_{j}\right) \\
\end{array}$ \\
\hline São Gabriel d'Oeste & 0.4606 & $63.09 \%$ \\
\hline Carazinho & 0.4252 & $65.36 \%$ \\
\hline Rio Verde & 0.4161 & $65.96 \%$ \\
\hline Rondonópolis & 0.3856 & $68.00 \%$ \\
\hline Rondonópolis & 0.3747 & $68.75 \%$ \\
\hline Carazinho & 0.3685 & $69.18 \%$ \\
\hline São Gabriel d'Oeste & 0.3682 & $69.20 \%$ \\
\hline Rondonópolis & 0.3652 & $69.41 \%$ \\
\hline São Gabriel d'Oeste & 0.3579 & $69.91 \%$ \\
\hline Rondonópolis & 0.3574 & $69.95 \%$ \\
\hline Carazinho & 0.3546 & $70.15 \%$ \\
\hline São Gabriel d'Oeste & 0.3514 & $70.37 \%$ \\
\hline Carazinho & 0.3465 & $70.72 \%$ \\
\hline Carazinho & 0.3465 & $70.72 \%$ \\
\hline São Gabriel d'Oeste & 0.3317 & $71.77 \%$ \\
\hline Rondonópolis & 0.3307 & $71.84 \%$ \\
\hline Rondonópolis & 0.3272 & $72.09 \%$ \\
\hline Rondonópolis & 0.3161 & $72.90 \%$ \\
\hline Carazinho & 0.3080 & $73.49 \%$ \\
\hline Carazinho & 0.3032 & $73.85 \%$ \\
\hline São Gabriel d'Oeste & 0.2987 & $74.18 \%$ \\
\hline Carazinho & 0.2962 & $74.36 \%$ \\
\hline Rondonópolis & 0.2931 & $74.59 \%$ \\
\hline Ronđonópolis & 0.2906 & $74.78 \%$ \\
\hline Carazinho & 0.2903 & $74.80 \%$ \\
\hline Rio Verde & 0.2769 & $75.81 \%$ \\
\hline Carazinho & 0.2738 & $76.05 \%$ \\
\hline São Gabriel d'Oeste & 0.2727 & $76.13 \%$ \\
\hline Rio Verde & 0.2722 & $76.17 \%$ \\
\hline
\end{tabular}


Continuação

\begin{tabular}{|c|c|c|}
\hline Região & $u_{j}$ & $\begin{array}{c}\text { Eficiência } \\
\text { Técnica } E\left(-u_{j}\right)\end{array}$ \\
\hline Rondonópolis & 0.2715 & $76.22 \%$ \\
\hline São Gabriel d'Oeste & 0.2688 & $76.43 \%$ \\
\hline São Gabriel d'Oeste & 0.2674 & $76.54 \%$ \\
\hline Carazinho & 0.2643 & $76.77 \%$ \\
\hline Rio Verde & 0.2632 & $76.86 \%$ \\
\hline Carazinho & 0.2537 & $77.59 \%$ \\
\hline Rondonópolis & 0.2515 & $77.76 \%$ \\
\hline Carazinho & 0.2495 & $77.92 \%$ \\
\hline Rondonópolis & 0.2465 & $78.15 \%$ \\
\hline São Gabriel d'Oeste & 0.2470 & $78.22 \%$ \\
\hline São Gabriel d'Oeste & 0.2406 & $78.62 \%$ \\
\hline Rondonópolis & 0.2277 & $79.64 \%$ \\
\hline Rondonópolis & 0.2257 & $79.80 \%$ \\
\hline São Gabriel d'Oeste & 0.2252 & $79.84 \%$ \\
\hline São Gabriel d'Oeste & 0.2251 & $79.84 \%$ \\
\hline Rondonópolis & 0.2236 & $79.96 \%$ \\
\hline São Gabriel a'Oeste & 0.2212 & $80.16 \%$ \\
\hline Carazinho & 0.2194 & $80.30 \%$ \\
\hline Carazinho & 0.2167 & $80.52 \%$ \\
\hline Carazinho & 0.2152 & $80.64 \%$ \\
\hline Rondonópolis & 0.2135 & $80.78 \%$ \\
\hline Carazinho & 0.2131 & $80.81 \%$ \\
\hline Carazinho & 0.2112 & $80.96 \%$ \\
\hline Carazinho & 0.2052 & $81.45 \%$ \\
\hline São Gabriel d'Oeste & 0.2017 & $81.73 \%$ \\
\hline São Gabriel d'Oeste & 0.1968 & $82.14 \%$ \\
\hline Carazinho & 0.1961 & $82.19 \%$ \\
\hline São Gabriel d'Oeste & 0.1919 & $82.54 \%$ \\
\hline
\end{tabular}


Continuação

\begin{tabular}{|c|c|c|}
\hline Região & $u_{j}$ & $\begin{array}{c}\text { Eficiência } \\
\text { Técnica } E\left(-u_{j}\right)\end{array}$ \\
\hline Carazinho & 0.1908 & $82.63 \%$ \\
\hline Carazinho & 0.1892 & $82.76 \%$ \\
\hline Carazinho & 0.1858 & $83.04 \%$ \\
\hline Ronđonópolis & 0.1858 & $83.04 \%$ \\
\hline São Gabriel d'Oeste & 0.1771 & $83.76 \%$ \\
\hline Rondonópolis & 0.1771 & $83.76 \%$ \\
\hline Rondonópolis & 0.1700 & $84.37 \%$ \\
\hline Rio Verde & 0.1647 & $84.81 \%$ \\
\hline Carazinho & 0.1632 & $84.94 \%$ \\
\hline Rio Verde & 0.1623 & $85.02 \%$ \\
\hline São Gabriel d'Oeste & 0.1577 & $85.41 \%$ \\
\hline Carazinho & 0.1562 & $85.54 \%$ \\
\hline Rondonópolis & 0.1558 & $85.57 \%$ \\
\hline São Gabriel d'Oeste & 0.1529 & $85.82 \%$ \\
\hline Carazinho & 0.1393 & $87.00 \%$ \\
\hline Rio Verde & 0.1379 & $87.12 \%$ \\
\hline Rio Verde & 0.1289 & $87.91 \%$ \\
\hline Rondonópolis & 0.1274 & $88.00 \%$ \\
\hline Carazinho & 0.1227 & $88.45 \%$ \\
\hline Carazinho & 0.1196 & $88.73 \%$ \\
\hline Carazinho & 0.1103 & $89.56 \%$ \\
\hline Carazinho & 0.1100 & $89.58 \%$ \\
\hline Rondonópolis & 0.1060 & $89.94 \%$ \\
\hline Rondonópolis & 0.0715 & $93.10 \%$ \\
\hline
\end{tabular}

Fonte: Dados da pesquisa 


\section{APÊNDICE 4}

Cálculo da eficiência técnica média. 


\section{Demonstração}

$$
\begin{aligned}
& \mathrm{ET}=2\left[1-\mathrm{F}\left(\sigma_{\mathrm{u}}\right)\right] \exp \left(1 / 2 \sigma_{u}{ }^{2}\right) \\
& \sigma_{\mathrm{u}}=0.42678 \\
& \sigma_{\mathrm{u}}^{2}=0.18214 \\
& \mathrm{ET}=2\left[1-\mathrm{F}(0.42678)^{10}\right] \exp (1 / 20.18214) \\
& \mathrm{ET}=2(1-0.6664) \text { exp }(0.09107) \\
& \mathrm{ET}=2(0.3336)(1.09535) \\
& \mathrm{ET}=(0.6672)(1.09535) \\
& \mathrm{ET}=0.7308
\end{aligned}
$$


APÊNDICE 5

Estatísticas descritivas das variáveis utilizadas no presente estudo. 
Tabela 9. Estatísticas descritivas das variáveis utilizadas

\begin{tabular}{lrr}
\hline Variáveis & Média & Desvio Padrão \\
\hline Produção (Valor) & $5.390 .627,70$ & $5.780 .354,01$ \\
Terra (ha) & 307,8 & 345,9 \\
Mão-de-obra (DH) & 1259,10 & 1053,71 \\
Insumos modernos (Valor) & $3.715 .111,00$ & $4.081 .241,58$ \\
$\begin{array}{l}\text { Experiência (anos) } \\
\text { Escolaridade (anos) }\end{array}$ & 10,30 & 8,98 \\
$\begin{array}{l}\text { Contatos com extensão } \\
\text { pública (número) }\end{array}$ & 8,31 & 51,22 \\
$\begin{array}{l}\text { Contatos com } \\
\text { particular (número) }\end{array}$ & 14,12 & 26,15 \\
\hline $\begin{array}{l}\text { Fonte: Dados da pesquisa. } \\
\text { Nota: valores expressos em crș de julho de 1990. }\end{array}$
\end{tabular}

